\title{
The Antibacterial Effects of Resin-Based Dental Sealants: A Systematic Review of In Vitro Studies
}

\author{
Saad Saeed AlShahrani ${ }^{1,+}$, Mana'a Saleh AlAbbas ${ }^{1,+}$, Isadora Martini Garcia ${ }^{2} \mathbb{D}$, Maha Ibrahim AlGhannam ${ }^{1}$, \\ Muath Abdulrahman AlRuwaili ${ }^{1}$, Fabrício Mezzomo Collares ${ }^{2}$ (D) and Maria Salem Ibrahim ${ }^{3, *(D)}$ \\ 1 College of Dentistry, Imam Abdulrahman Bin Faisal University, Dammam 31441, Saudi Arabia; \\ 2150008724@iau.edu.sa (S.S.A.); 2160006146@iau.edu.sa (M.S.A.); 2170001326@iau.edu.sa (M.I.A.); \\ 2160004214@iau.edu.sa (M.A.A.) \\ 2 Dental Materials Laboratory, Department of Conservative Dentistry, School of Dentistry, Federal University of \\ Rio Grande do Sul, Porto Alegre 90035-003, Brazil; isadora.garcia@ufrgs.br (I.M.G.); \\ fabricio.collares@ufrgs.br (F.M.C.) \\ 3 Department of Preventive Dental Sciences, College of Dentistry, Imam Abdulrahman Bin Faisal University, \\ Dammam 34212, Saudi Arabia \\ * Correspondence: msibrahim@iau.edu.sa \\ + Co-first author: These authors contributed equally to this work.
}

Citation: AlShahrani, S.S.; AlAbbas, M.S.; Garcia, I.M.; AlGhannam, M.I.; AlRuwaili, M.A.; Collares, F.M.; Ibrahim, M.S. The Antibacterial Effects of Resin-Based Dental Sealants: A Systematic Review of In Vitro Studies. Materials 2021, 14, 413. https:/ /doi.org/10.3390/ma14020413

Received: 22 December 2020

Accepted: 12 January 2021

Published: 15 January 2021

Publisher's Note: MDPI stays neutral with regard to jurisdictional clai$\mathrm{ms}$ in published maps and institutional affiliations.

Copyright: $\odot 2021$ by the authors. Licensee MDPI, Basel, Switzerland. This article is an open access article distributed under the terms and conditions of the Creative Commons Attribution (CC BY) license (https:// creativecommons.org/licenses/by/ $4.0 /)$.

\begin{abstract}
This review aimed to assess the antimicrobial effects of different antibacterial agents/ compounds incorporated in resin-based dental sealants. Four databases (PubMed, MEDLINE, Web of Science and Scopus) were searched. From the 8052 records retrieved, 275 records were considered eligible for full-text screening. Nineteen studies met the inclusion criteria. Data extraction and quality assessment was performed by two independent reviewers. Six of the nineteen included studies were judged to have low risk of bias, and the rest had medium risk of bias. Compounds and particles such as zinc, tin, Selenium, chitosan, chlorhexidine, fluoride and methyl methacrylate were found to be effective in reducing the colony-forming unit counts, producing inhibition zones, reducing the optical density, reducing the metabolic activities, reducing the lactic acid and polysaccharide production and neutralizing the $\mathrm{pH}$ when they are added to the resin-based dental sealants. In addition, some studies showed that the antibacterial effect was not significantly different after 2 weeks, 2 months and 6 months aging in distilled water or phosphate-buffered saline. In conclusion, studies have confirmed the effectiveness of adding antibacterial agents/compounds to dental sealants. However, we should consider that these results are based on laboratory studies with a high degree of heterogeneity.
\end{abstract}

Keywords: sealant; antibacterial; caries prevention

\section{Introduction}

Dental caries is a highly prevalent chronic disease, affecting more than $60 \%$ of school children [1,2]. Caries is a biofilm-sugar-dependent disease. The bacteria in the biofilm over the teeth metabolize fermentable carbohydrates and produce acids [3]. The acids demineralize the hydroxyapatite (HAp) of dental tissues (enamel and dentin), leading to an irreversible process over time [3].

The loss of minerals is considered as an unbalance in the natural demineralizationremineralization process of teeth, and it causes caries lesions to have several stages. In the early stages, carious lesions have subclinical characteristics [4]. However, if the biofilm persists over the teeth due to poor oral hygiene and frequent consumption of fermentable carbohydrates such as sucrose, there will be a periodic reduction in the $\mathrm{pH}$ of the oral environment [4]. In such scenarios, dental caries becomes clinically visible in the form of white-spot lesions [4]. Initial non-cavitated white lesions may become cavitated if the process of demineralization continues without the process of remineralization. Although these carious lesions usually get restored, recurrent caries could appear around the restorations [5]. Each time the restoration is replaced, dental tissue is eventually removed. This 
process, identified as "tooth death spiral", can lead to total tooth loss [6]. Therefore, prevention and intervention at the beginning of the disease are essential to prevent teeth loss.

Besides being a sugar-dependent biofilm, dental caries is influenced by the individual's behavior, education and social class. These factors can modify the severity of the disease [5]. Because of the multifactorial nature of caries, it is important to assess the susceptibility of each individual patient to dental caries and decide which preventive measures could be used in each case $[7,8]$. Acidic gels with high fluoride concentrations are often used topically to treat initial lesions since fluoride-in biofilm and oral fluids-helps to inhibit the demineralization process and induce the remineralization of teeth [9]. Moreover, diet and hygiene instructions must always be present as part of caries prevention measures. In addition to these measures, the application of light-polymerizable resin-based sealants to mechanically seal dental surfaces is a procedure with a reasonable success rate in preventing occlusal caries [7].

Dental sealants are used mainly for sealing occlusal surfaces, which are highly susceptible to biofilm accumulation [7]. Sealants are commonly used right after the full eruption of the first permanent molars around six years of age. Sealants have been reported to reduce the incidence of caries by around $80 \%$ among children at high caries risk [7]. However, around $20 \%$ of children at a high-caries risk still develop new lesions even with dental sealants [7]. Therefore, improvements in the composition of sealants have been suggested to increase their efficacy.

Traditional sealants in the market are based on methacrylate resins with no or little bioactivity such as antibacterial or remineralizing properties. They are usually composed only of conventional monomers, such as bisphenol glycidyl methacrylate (BisGMA) and triethylene glycol dimethacrylate (TEGDMA), and inorganic particles such as fluoroaluminosilicate glass powder [10-13]. Due to the well-known action of fluoride against dental caries [14], some manufacturers have added this element in the composition of sealants [7]. However, until now, the addition of fluoride in sealants does not seem to have a remarkable effect on preventing caries progression or reducing the incidence of new carious lesions [7]. The reason for that is probably because fluoride will be released over time from the resin matrix due to its lack of binding to the polymer [15]. Other compounds such as sodium monofluorophosphate, bioglasses and nanoamorphous calcium phosphate were also investigated to prevent caries at the sealant-tooth interface [16-19].

Recently, research has focused on the improvement of antibacterial activity that sealants could present [20-23]. These agents would benefit from providing an improved therapeutic action to the material by reducing the chance of bacteria colonization and biofilm formation at the tooth-sealant interface. This approach may reduce the incidence of new lesions in the teeth of children at high risk of caries. There is a wide range of tests applied to evaluate the antibacterial activity of these materials. However, no studies summarized the information available to date in the literature on sealants with antimicrobial agents. This review aimed to identify the antibacterial agents incorporated into resin-based dental sealants and analyze which methods were applied to evaluate the performance of these materials. In addition, the review aimed to evaluate the quality of evidence.

\section{Materials and Methods}

\subsection{Research Question}

The main review question was what are the antibacterial effects of resin-based dental sealants that incorporate antibacterial agents in their structure? The review followed the Preferred Reporting Items for Systematic Reviews and Meta-Analyses (PRISMA) guidelines for systematic reviews and meta-analysis [24]. The review protocol was pre-determined but not published. 


\subsection{Search Strategies}

The search strategies of the four electronic databases are described in Table 1. They were developed and applied by three authors (M.S.A, M.I.A. and M.S.I.). The last search was run on 1 June 2020. No date or language restriction was applied at this stage. The resulting citations from all databases were imported to Covidence online platform for screening.

Table 1. Search strategies.

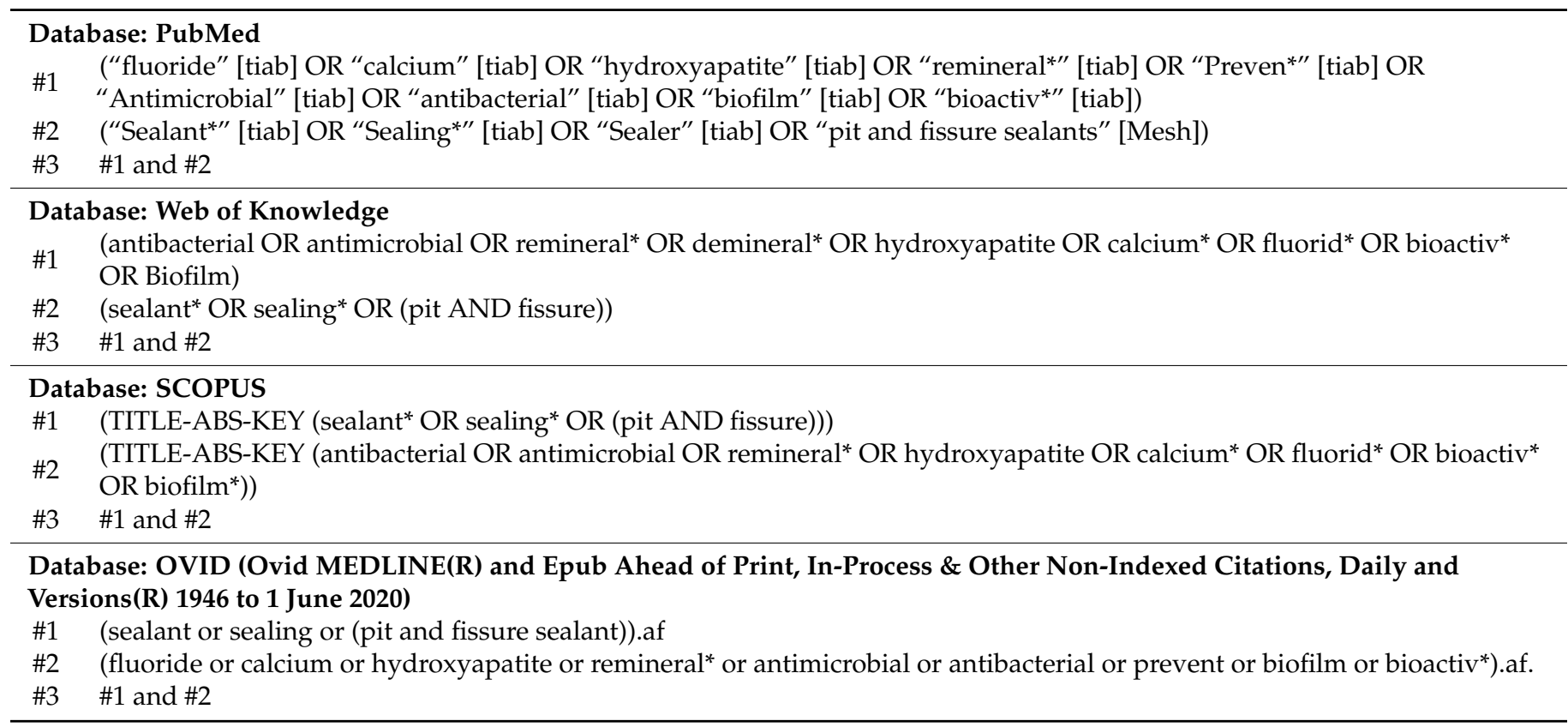

\subsection{Inclusion and Exclusion Criteria}

Studies included in this review were in vitro, laboratory studies that assessed the antimicrobial activities of resin-based dental sealants. Studies that are not laboratory studies, studies that did not have resin-based sealants, studies that only tested resinmodified glass ionomer and studies that did not assess any antibacterial activity were excluded. The compositions on commercial resin-based sealants were searched through the safety data sheet of the material itself or the literature to confirm that the sealant is a resin-based material.

\subsection{Studies Screening and Selection}

Selection of the studies was performed using a pair of reviewers (M.S.A., M.I.A. and M.A.A.). Reviewers were not blinded to the identity of the authors or journal. The selection process consisted of title and abstract screening then full text screening. If any of the exclusion criteria were found, the record was excluded. Disagreements among reviewers were solved by a senior reviewer (M.S.I.).

\subsection{Data Extraction}

Two reviewers (S.S.A and M.S.I.) extracted data regarding various variables from the included studies using customized data collection forms. The extracted data included qualitative and quantitative data. The following data were extracted: the details of the sample including sample size, type, measurements and curing time, assessment methods used to assess the antibacterial effect, other properties assessed beside antibacterial properties, the antibacterial agents, bacteria or type of inoculum used and the control and tested (interventional) groups details. In addition, data about the outcome measures, in regard to units and effects, were extracted. 


\subsection{Quality Assessment}

The risk of bias of the included studies was assessed by three independent reviewers (S.S.A, M.S.A and M.S.I.). The assessment tool was adapted from previously published scoping and systematic reviews $[25,26]$. Studies with one to three "Yes" only were considered to have a low risk of bias. Studies scoring four to six "Yes" or seven to nine "Yes" were considered to have a medium risk of bias or a high risk of bias, respectively.

\subsection{Assessment of Heterogeneity}

Two reviewers (S.S.A. and M.S.I.) extracted data about the interventional, methodological and statistical heterogeneities of the included studies. Interventional heterogeneity was assessed by checking the differences in compositions of the tested groups and control groups among the included studies, such as the percentage and type of the fillers and incorporation of other agents such remineralizing agents. Methodological heterogeneity was assessed by extracting data in regard to the sample types, curing time, bacteria type or inoculum source, the methods of outcome assessment and the study's overall risk of bias.

\subsection{Data Synthesis}

A qualitative summary of the assessment methods, interventions, outcomes and any additional relevant information was planned to be reported. We also planned to perform a quantitative meta-analysis using a fixed-effect model or a random-effect model if an $\mathrm{I}_{2}$ statistics at or below $50 \%$ was found with no significant methodological heterogenicity or an $\mathrm{I}_{2}$ statistics was found to be above $50 \%$ with no significant methodological heterogenicities, respectively. On the other hand, if a significant statistical heterogeneity or a methodological heterogenicity was found, a meta-analysis was not planned to be conducted.

\section{Results}

\subsection{Studies Selection}

A total number of 10,103 potentially relevant records were retrieved from the four databases. Duplicates were initially removed by Covidence.org and 8052 records included for abstract and title screening. Two hundred and seventy-five records were eligible for full-text screening. Nineteen records met the inclusion criteria and were included in the review. The screening process is reported in Figure 1. 


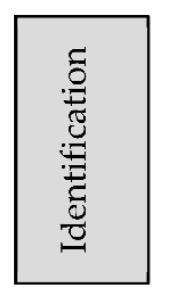

Records identified through databases searching:

1. PubMed $(n=4920)$

2. MEDLINE $(n=2518)$

3. Web of Science $(n=2039)$

4. Scopus $(n=2626)$
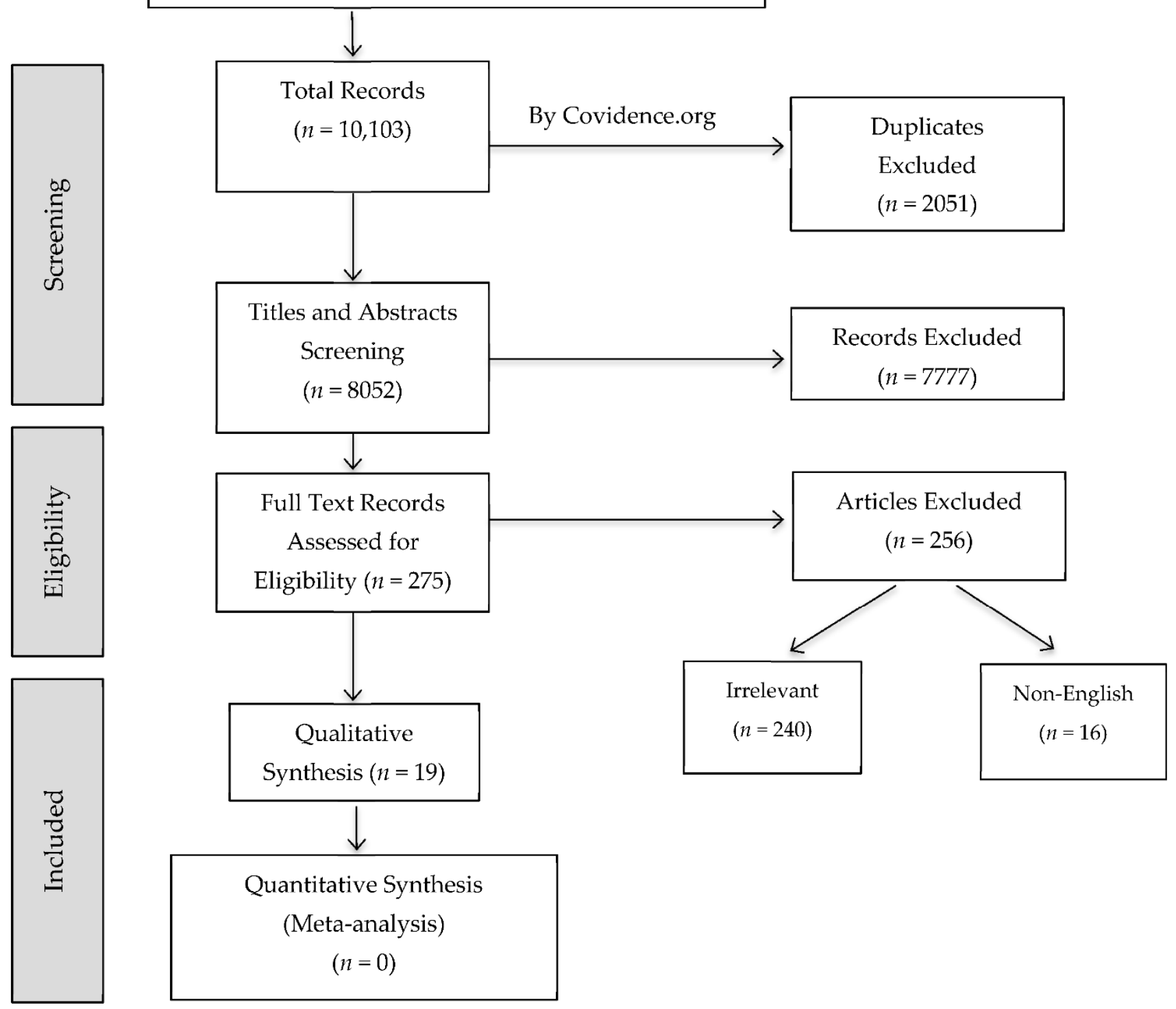

Figure 1. Flow diagram of study screening and selection.

\subsection{Risk of Bias Appraisal}

Out of the 19 included studies, six were judged to have low risk of bias, and the rest were of medium risk of bias (Table 2). Sample size calculation and blinding were not reported in all of the included studies, which led to a positive risk of bias in these two parameters (Figure 2). Studies always reported the sample preparation or measurements and there was always at least one method of quantitative assessment (Figure 2). 
Table 2. Risk of bias appraisal.

\begin{tabular}{|c|c|c|c|c|c|c|c|c|c|c|}
\hline \multirow[b]{2}{*}{ Study } & \multicolumn{2}{|c|}{ Sampling Bias } & \multicolumn{3}{|c|}{ Assessment Bias } & \multicolumn{2}{|c|}{ Reporting Bias } & \multirow{2}{*}{$\begin{array}{c}\text { Funding } \\
\text { Bias }\end{array}$} & \multirow{2}{*}{$\begin{array}{l}\text { Conflict } \\
\text { Bias }\end{array}$} & \multirow{2}{*}{ Risk of Bias } \\
\hline & $\begin{array}{l}\text { Sample Size } \\
\text { Calculation }\end{array}$ & $\begin{array}{c}\text { Sample } \\
\text { Preparation }\end{array}$ & Blinding & $\begin{array}{l}\text { Assessment } \\
\text { Methods }\end{array}$ & $\begin{array}{c}\text { Presence of } \\
\text { Control Group }\end{array}$ & $\begin{array}{l}\text { Definitive } \\
\text { Values }\end{array}$ & $\begin{array}{c}\text { Quantitative } \\
\text { Analysis }\end{array}$ & & & \\
\hline Coco et al., 2020 [10] & + & - & + & - & - & + & - & - & - & Low \\
\hline Garcia et al., 2020 [11] & + & - & + & + & - & - & - & - & - & Low \\
\hline Ibrahim et al., 2020 [21] & + & - & + & - & - & + & - & - & + & Medium \\
\hline Monteiro et al., 2020 [12] & + & - & + & + & - & - & - & - & - & Low \\
\hline Ibrahim et al., 2019 [27] & + & - & + & - & - & + & - & - & + & Medium \\
\hline Swetha et al., 2019 [28] & + & - & + & + & - & - & - & - & - & Low \\
\hline Zmener et al., 2019 [29] & + & - & + & + & - & - & - & - & + & Medium \\
\hline Yu et al., 2016 [30] & + & - & + & - & - & + & - & - & + & Medium \\
\hline Rajabnia et al., 2016 [31] & + & - & + & + & - & - & - & - & - & Low \\
\hline Shanmugaavel et al., 2015 [32] & + & - & + & + & - & - & - & - & - & Low \\
\hline Hamilton et al., 2014 [33] & + & - & + & + & - & + & - & + & + & Medium \\
\hline Tran et al., 2013 [13] & + & - & + & - & - & + & - & - & + & Medium \\
\hline Mahapoka et al., 2012 [34] & + & - & + & - & - & - & - & - & + & Medium \\
\hline Feng Li et al., 2011 [35] & + & - & + & - & - & + & - & - & + & Medium \\
\hline Kumar et al., 2010 [36] & + & - & + & + & + & - & - & + & + & Medium \\
\hline Matalon et al., 2003 [39] & + & - & + & - & $+^{*}$ & - & - & + & + & Medium \\
\hline Loyola-Rodriguez et al., 1996 [40] & + & - & + & + & $+* *$ & - & - & + & + & Medium \\
\hline
\end{tabular}

$(+)$ Yes; $(-)$ no; $\left(^{*}\right)$ they used only blank well/disc.; $\left.{ }^{* *}\right)$ they used commercially available sealant but not the same resin matrix as the experimental group. 


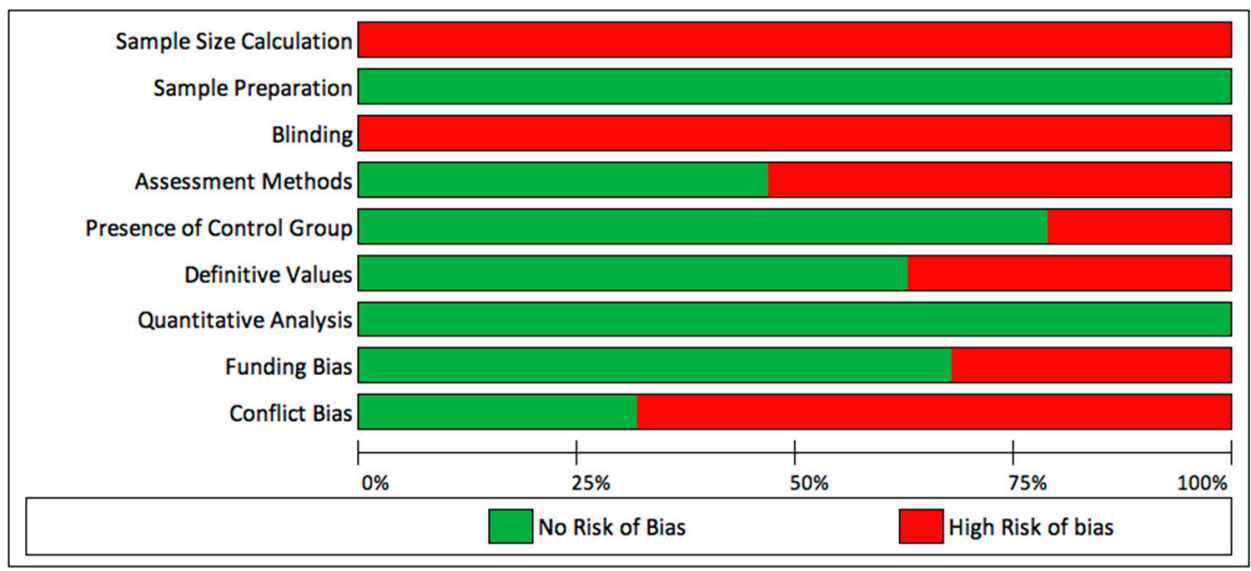

Figure 2. Overall risk of bias for each parameter.

\subsection{Studies Characteristics}

A summary about the characteristics of the 19 included studies is reported in Table 3.

\subsubsection{Samples}

Out of the 19 included studies, only one study [29] used human teeth samples and one study used bovine teeth samples [37], while most of the studies used discs samples of the same material. There was a large variation between the studies in regard to the number of samples used to assess the antibacterial effect. This variation was also found between different tests in the same study. The light-curing/polymerization time was reported in most of the studies and showed variation. However, five studies $[10,13,32,39,40]$ did not report any specific time.

\subsubsection{Antibacterial Agents/Compounds}

Studies investigated various antibacterial agents / compounds including zinc methacrylate $(\mathrm{ZnM})$, tin methacrylate $(\mathrm{SnM})$, zinc oxide $(\mathrm{ZnO})$, organo-selenium, chitosan, chlorhexidine $(\mathrm{CHX})$, calcium fluoride $\left(\mathrm{CaF}_{2}\right)$, 2-methacryloxylethyl dodecyl methyl ammonium bromide (MAE-DB), 2-methacryloyloxyethyl trimethylammonium chloride (METAC), methacryloxylethyl cetyl dimethyl ammonium chloride (DMAE-CB), dimethylaminohexadecyl methacrylate (DMAHDM) and 1,3,5-triacryloyl hexahydro-1,3,5-triazine (TAT) (Table 3). Fluoride was the most commonly incorporated agent in different studies [28,36-40].

\subsubsection{Bacteria and Inoculum}

Most studies (17 studies) tested the antibacterial activities of the sealants against S. mutans. One study [21] tested the effect against multispecies biofilms cultured from pooled saliva of high-caries risk and low-caries risk pediatric dental patients, and another study tested the effect against Enterococcus faecalis [29]. Other bacteria such as L. acidophilus [28,32,37,38], S. oralis [10], C. albicans [10], S. salivarius [13] and S. sobrinus [40] were also used to test the antibacterial effects.

\subsubsection{Antibacterial Activity Assessment Methods}

Studies investigated the antibacterial effects of the studied sealants using various assessment methodologies and tests (Table 3). The most common assessment method was a colony forming unit (CFU) counting test $[10-13,21,27,28,30,34,35]$, followed by an inhibition zone test [13,32-34,36-40]. Other methods such as optical density [35,37,39], bacterial leakage [29], scanning electron microscopy [10,33], confocal laser scanning microscopy $[13,21,27,30]$ and bacterial genomic profiling [21] were also used. Some bacterial activities and properties such as lactic acid production [21,27], metabolic activities [21,27,30], polysaccharides production [27], tolerance to acid and oxygen [27] and $\mathrm{pH}$ [10,27] were also assessed in a few of the included studies. 


\subsubsection{Other Properties and Tests}

Beside assessing the antibacterial effects, some studies investigated other properties such as fluoride release, degree of conversion, shear-bond strength, microhardness, compressive strength, tensile strength, flexural strength, depth of cure, softening, cytotoxicity and microleakage (Table 3).

\subsubsection{Control and Tested Groups}

There was a variation in the materials used as control groups between the included studies (Table 3). Tested groups were either commercially available sealant materials or newly developed sealant materials.

\subsection{Summary of Findings}

Summaries of the findings are presented in Tables 4 and 5.

Studies that used CFU counting to assess the antibacterial effects found a significant reduction in CFU counts with 5\% ZnM [10], 2.5 and 5\% SnM [10], 2.5 and 5\% METAC [11], 5\% DMAHDM [21,27], 2\% TAT [12], 0.5 and $1 \% \mathrm{ZnO}$ [28], 0.5 and $1 \% \mathrm{CaF}_{2}$ [28], 4\% MAEDB [30], 2, 2.5, 3, 4 and 5\% chitosan [31,34], 0.25, 0.5 and 1\% Se [13], Teethmate F-1 [34], Seal \& Protect [34] and 1\% DMAE-CB [35] sealants in comparison to the controls or other tested groups (Table 4). There was a wide variation in the data reported among the included studies. The antibacterial effect of the antibacterial sealants was not significantly different after 2 weeks, 50 days, 2 months and 6 months aging in distilled water or phosphatebuffered saline $[11,13,30,35,39]$.

Studies that assessed the antibacterial effects using an inhibition zone test reported the use of 1\% CHX [32], 0.12\% CHX [33], 0.25\% Se [13], 2 and 2.5\% chitosan [34], Teethmate F1 [34,36,37,40], Seal \& Protect [34], Clinpro [37] and Dryact Seal [39] sealants in comparison to the controls or other tested groups (Table 4).

The results of other studies that used optical density, bacterial leakage, scanning electron microscopy, confocal laser scanning microscopy and bacterial genomic profiling to report the antibacterial effects of the tested materials are reported in Table 4. Other bacterial activities such lactic acid production, metabolic activities, polysaccharide production and $\mathrm{pH}$ after exposure to various tested antibacterial resin-based sealants were reported in a few studies (Table 5). 
Table 3. Characteristics of included studies.

\begin{tabular}{|c|c|c|c|c|c|c|c|c|c|}
\hline Study & $\begin{array}{c}\text { Group } \\
\text { Sample Size }\end{array}$ & $\begin{array}{l}\text { Sample Type or } \\
\text { Measurements }\end{array}$ & $\begin{array}{l}\text { Light } \\
\text { Curing } \\
\text { Time }\end{array}$ & $\begin{array}{l}\text { Assessment } \\
\text { Methods }\end{array}$ & Bacteria & Antibacterial Agents & $\begin{array}{l}\text { Other Tests/Properties } \\
\text { Assessed }\end{array}$ & Control Groups & Tested Groups \\
\hline $\begin{array}{l}\text { Cocco et al., } \\
2020[10]\end{array}$ & 4 & $\begin{array}{l}\text { Sealants were } \\
\text { applied and } \\
\text { polymerized on HA } \\
\text { discs }(1.25 \mathrm{~cm} \text { in } \\
\text { diameter })\end{array}$ & - & $\begin{array}{l}\text { CFU } \\
\text { SEM } \\
\mathrm{pH}\end{array}$ & $\begin{array}{l}\text { S. mutans } \\
\text { S. oralis } \\
\text { C. albicans }\end{array}$ & $\begin{array}{c}\text { Zinc methacrylate (ZnM) } \\
\text { di-nbutyldimethacrylate- } \\
\text { tin } \\
\text { (SnM) }\end{array}$ & $\begin{array}{c}\text { DC } \\
\text { Translucency parameter } \\
\text { microshear bond strength } \\
\text { FS } \\
\text { Depth of cure } \\
\text { Cytotoxicity assay }\end{array}$ & $\begin{array}{c}\text { Resin Base }=\text { TEGDMA }+ \\
\text { BisGMA + glycerol } \\
\text { dimethacrylate } \\
\text { phosphate + Water +, } \\
\text { phenylbis } \\
(2,4,6 \text {-tri-methylbenzoyl)- } \\
\text { phosphine oxide }+ \\
\text { diphenyliodo- nium } \\
\text { hexafluorophosphate + } \\
\text { nanometric silica }\end{array}$ & $\begin{array}{c}\text { Resin Base + 2.5\% ZnM } \\
\text { Resin Base + 5\% ZnM } \\
\text { Resin Base + 2.5\% SnM } \\
\text { Resin Base + 5\% SnM }\end{array}$ \\
\hline $\begin{array}{c}\text { Garcia } \\
\text { et al., 2020 } \\
{[11]}\end{array}$ & 3 & $\begin{array}{c}4 \mathrm{~mm} \text { diameter } \times 1 \\
\mathrm{~mm} \text { thickness }\end{array}$ & $\begin{array}{l}30 \mathrm{~s} \text { on } \\
\text { each side }\end{array}$ & $\begin{array}{c}\mathrm{CFU} \\
\text { (with or without aging for } 50 \\
\text { days in distilled water) }\end{array}$ & S. mutans & $\begin{array}{l}\text { [2(methacryloyloxy)ethyl] } \\
\text { trimethylammonium } \\
\text { chloride (METAC) }\end{array}$ & $\begin{array}{c}\text { DC } \\
\text { Softening in solvent } \\
\text { Ultimate tensile strength } \\
\text { Contact angle and SFE } \\
\text { microshear bond strength } \\
\text { and cytotoxicity } \\
\text { evaluation } \\
\text { (with and without aging } \\
\text { for } 50 \text { days in distilled } \\
\text { water at } 37^{\circ} \mathrm{C} \text {.) }\end{array}$ & $\begin{array}{c}60 \mathrm{wt} \% \text { BisGMA }+40 \mathrm{wt} \\
\% \text { TEGDMA }+1 \mathrm{~mol} \% \\
\mathrm{CQ}+1 \mathrm{~mol} \% 4 \mathrm{E}+0 \mathrm{wt} \\
\% \text { METAC }\end{array}$ & $\begin{array}{c}60 \mathrm{wt} \% \text { BisGMA + } 40 \mathrm{wt} \\
\% \text { TEGDMA + } 1 \mathrm{~mol} \% \\
\text { CQ + } 1 \text { mol } \% 4 \mathrm{E}+2.5 \mathrm{wt} \\
\% \mathrm{METAC} \\
60 \mathrm{wt} \% \text { BisGMA + } 40 \mathrm{wt} \\
\% \text { TEGDMA }+1 \mathrm{~mol} \% \\
\text { CQ + } 1 \text { mol } \% 4 \mathrm{E}+5 \mathrm{wt} \\
\% \text { METAC }\end{array}$ \\
\hline $\begin{array}{l}\text { Ibrahim } \\
\text { et al., } 2020 \\
\text { [21] }\end{array}$ & $\begin{array}{c}\text { Genomic } \\
\text { profiling }=3 \\
\text { CLSM }=2 \\
6 \times 3 \text { repetition } \\
\text { (all other) }\end{array}$ & $\begin{array}{c}9 \text { mm diameter } \times 2 \\
\text { mm thickness }\end{array}$ & $\begin{array}{l}60 \mathrm{~s} \text { on } \\
\text { each side }\end{array}$ & $\begin{array}{c}\text { CFU } \\
\text { Metabolic Activity (MTT) } \\
\text { CLSM } \\
\text { Lactic Acid Production } \\
\text { Genomic Profiling of } \\
\text { Saliva-Derived Biofilms }\end{array}$ & $\begin{array}{l}\text { Pooled saliva from } \\
\text { healthy high and } \\
\text { low caries-risk } \\
\text { pediatric patients }\end{array}$ & $\begin{array}{l}\text { Dimethylaminohexadecyl } \\
\text { methacrylate } \\
\text { (DMAHDM) }\end{array}$ & - & $\begin{array}{c}50 \% \text { PEHB }(44.5 \% \\
\text { PMGDM + 39.5\% } \\
\text { EBPADMA + } 10 \% \text { HEMA } \\
+5 \% \text { BisGMA + } 1 \% \\
\text { BAPO }+50 \% \text { Glass } \\
\end{array}$ & $\begin{array}{c}45 \% \text { PEHB }+50 \% \text { Glass + } \\
0 \% \text { NACP + } 5 \% \\
\text { DMAHDM } \\
45 \% \text { PEHB + } \\
30 \% \text { Glass + 20\% NACP + } \\
5 \% \text { DMAHDM } \\
\end{array}$ \\
\hline $\begin{array}{l}\text { Monteiro } \\
\text { et al., 2020 } \\
\text { [12] }\end{array}$ & 3 & $\begin{array}{c}4 \mathrm{~mm} \text { diameter } \times 1 \\
\mathrm{~mm} \text { thickness }\end{array}$ & $\begin{array}{l}30 \mathrm{~s} \text { on } \\
\text { each side }\end{array}$ & $\mathrm{CFU}$ & S. mutans & TAT & $\begin{array}{c}\text { DC } \\
\text { Softening } \\
\text { Ultimate tensile strength } \\
\text { (UTS) } \\
\text { Contact angle and SFE }\end{array}$ & $\begin{array}{c}\text { Resin Base }=50 \mathrm{wt} \% \\
\text { BisGMA + } 50 \mathrm{wt} \% \\
\text { TEGDMA + } 1 \mathrm{~mol} \% \\
\text { CQ+4E + BHT 0.01\% + } \\
\text { Calcium Tungstate } 30 \mathrm{wt} \\
\%+0.7 \mathrm{wt} \% \text { Colloidal } \\
\text { silica } \\
\end{array}$ & $\begin{array}{l}\text { Resin Base }+2 \mathrm{wt} \% \\
\alpha-\mathrm{TCP}+2 \mathrm{wt} \% \mathrm{TAT}\end{array}$ \\
\hline $\begin{array}{l}\text { Ibrahim } \\
\text { et al., } 2019 \\
{[27]}\end{array}$ & $6 \times 3$ repetition & $\begin{array}{c}9 \text { mm diameter } \times 2 \\
\mathrm{~mm} \text { thickness }\end{array}$ & $\begin{array}{l}60 \mathrm{~s} \text { on } \\
\text { each side }\end{array}$ & $\begin{array}{c}\text { CFU } \\
\text { Metabolic Activity (MTT) } \\
\text { Polysaccharide Production } \\
\text { CLSM } \\
\text { Acid-Neutralizing Activity } \\
\text { Lactic Acid Production }\end{array}$ & S. mutans & $\begin{array}{l}\text { Dimethylaminohexdecyl } \\
\text { methacrylate } \\
\text { (DMAHDM) }\end{array}$ & - & $\begin{array}{c}\text { Virtuoso Flowable } \\
\text { Composite } \\
50 \% \text { PEHB }(44.5 \% \\
\text { PMGDM + 39.5\% } \\
\text { EBPADMA + 10\% HEMA } \\
+5 \% \text { BisGMA + } 1 \% \\
\text { BAPO }+50 \% \text { Glass }\end{array}$ & $\begin{array}{c}45 \% \text { PEHB }+50 \% \text { Glass + } \\
0 \% \text { NACP }+5 \% \\
\text { DMAHDM } \\
50 \% \text { PEHB }+30 \% \text { Glass + } \\
20 \% \text { NACP + } 0 \% \\
\text { DMAHDM } \\
45 \% \text { PEHB }+30 \% \text { Glass + } \\
20 \% \text { NACP + } 5 \% \\
\text { DMAHDM }\end{array}$ \\
\hline
\end{tabular}


Table 3. Cont

\begin{tabular}{|c|c|c|c|c|c|c|c|c|c|}
\hline Study & $\begin{array}{l}\text { Group } \\
\text { Sample Size }\end{array}$ & $\begin{array}{l}\text { Sample Type or } \\
\text { Measurements }\end{array}$ & $\begin{array}{l}\text { Light } \\
\text { Curing } \\
\text { Time }\end{array}$ & $\begin{array}{l}\text { Assessment } \\
\text { Methods }\end{array}$ & Bacteria & Antibacterial Agents & $\begin{array}{l}\text { Other Tests/Properties } \\
\text { Assessed }\end{array}$ & Control Groups & Tested Groups \\
\hline $\begin{array}{l}\text { Swetha } \\
\text { et al., 2019 } \\
\text { [28] }\end{array}$ & 7 & $\begin{array}{l}\text { Coating equal } \\
\text { amount } \\
\text { of sealant material } \\
\text { on to the walls of } \\
\text { eppendorf tubes }\end{array}$ & $\begin{array}{l}40 \mathrm{~s}(7 \\
\text { cycles } \\
\text { from the } \\
\text { top to } \\
\text { the } \\
\text { bottom } \\
\text { of the } \\
\text { tube) }\end{array}$ & Direct Contact Test (CFU) & $\begin{array}{l}\text { S. mutans } \\
\text { L. acidophilus }\end{array}$ & $\begin{array}{l}\text { Zinc Oxide }(\mathrm{ZnO}) \text { and } \\
\text { Calcium Fluoride }\left(\mathrm{CaF} F_{2}\right) \\
\text { nanoparticles }(\mathrm{NPs})\end{array}$ & $\begin{array}{l}\text { compressive and flexural } \\
\text { strengths }\end{array}$ & $\begin{array}{l}\text { Plain fissure sealant } \\
\text { (PFS) }\end{array}$ & $\begin{array}{c}\mathrm{PFS}+0.5 \text { or } 1 \mathrm{wt} \% \mathrm{ZnO} \\
\mathrm{PFS}+0.5 \text { or } 1 \mathrm{wt} \% \mathrm{CaF}_{2} \\
\mathrm{PFS}+0.5 \text { or } 1 \mathrm{wt} \% \mathrm{ZnO}+ \\
0.5 \text { or } 1 \mathrm{wt} \% \mathrm{CaF}_{2}\end{array}$ \\
\hline $\begin{array}{c}\text { Zmener } \\
\text { et al., } 2019 \\
\text { [29] }\end{array}$ & 10 & $\begin{array}{c}\text { Randomly assigned } \\
\text { cleaned, sterilized, } \\
\text { non-carries extracted } \\
\text { human third molars } \\
\text { without overfilling } \\
\text { the pit and fissures }\end{array}$ & $20 \mathrm{~s}$ & $\begin{array}{l}\text { Bacterial Leakage Testing } \\
\text { (frequencies and median } \\
\text { survival time) }\end{array}$ & $\begin{array}{l}\text { Enterococcus } \\
\text { faecalis }\end{array}$ & $\begin{array}{l}\text { Modified calcium } \\
\text { phosphate (MCP) }\end{array}$ & - & $\begin{array}{c}\text { Embrace Wet Bonda } \\
\text { (EWB) } \\
\text { A commercially available } \\
\text { P\&F sealant Clinpro } \\
\text { (CLPR) }\end{array}$ & EWB + MCP (EWBMCP) \\
\hline $\begin{array}{l}\text { Yu et al., } \\
2016 \text { [30] }\end{array}$ & $\begin{array}{c}\text { Metabolic } \\
\text { Activity }=6 \\
\text { CFU }=5\end{array}$ & $8 \mathrm{~mm}$ diameter & $20 \mathrm{~s}$ & $\begin{array}{c}\text { CFU } \\
\text { Metabolic Activity (Cell } \\
\text { Counting Kit-8) } \\
\text { CLSM } \\
\text { (All the tests with or without } \\
\text { aging } 6 \text { months in distilled } \\
\text { water) }\end{array}$ & S. mutans & $\begin{array}{l}\text { 2-methacryloxylethyl } \\
\text { dodecyl methyl } \\
\text { ammonium bromide } \\
\text { (MAE-DB) }\end{array}$ & - & $\begin{array}{c}\text { Eco-S Sealant } \\
\text { Clinpro }^{\mathrm{TM}} \text { Sealant }\end{array}$ & $\begin{array}{c}\text { Eco-S Sealant + } 4 \text { wt \% } \\
\text { MAE-DB }\end{array}$ \\
\hline $\begin{array}{l}\text { Shanmugaavel } \\
\text { et al., 2015 } \\
\text { [32] }\end{array}$ & 5 & $6 \mathrm{~mm}$ diameter & - & Inhibition Zone & $\begin{array}{l}\text { S. mutans } \\
\text { L. acidophilus }\end{array}$ & $\begin{array}{l}20 \% \text { chlorhexidine } \\
\text { digluconate liquid (CHX) }\end{array}$ & $\begin{array}{c}\text { Compressive strength } \\
\text { (CS) } \\
\text { diametrical } \\
\text { tensile strength }\end{array}$ & $\begin{array}{l}\text { Conventional glass } \\
\text { ionomer sealants (GIS) } \\
\text { (Fuji VII) } \\
\text { Clinpro }\end{array}$ & $\begin{array}{c}\text { GIS }+1 \% \text { CHX } \\
\text { Clinpro }+1 \% \text { CHX }\end{array}$ \\
\hline $\begin{array}{c}\text { Hamilton } \\
\text { et al., 2014 } \\
\text { [33] }\end{array}$ & 10 & $\begin{array}{c}5 \mathrm{~mm} \text { diameter } \times 2 \\
\mathrm{~mm} \text { thickness }\end{array}$ & $40 \mathrm{~s}$ & Inhibition Zone & S. mutans & $\begin{array}{l}\text { Electrospun nylon-6 (N6) } \\
\quad+\text { Chitosan }(\mathrm{CH})\end{array}$ & $\begin{array}{c}\text { Flexural strength } \\
\text { Vickers microhardness }\end{array}$ & $\begin{array}{l}\text { Helioseal Clear } \\
0.12 \% \text { Chlorhexidine } \\
\text { (CHX) solution }\end{array}$ & $\begin{array}{c}\text { Resin Base }=60 \% \\
\text { Bis-GMA }+40 \% \\
\text { TEGDMA + 0.5\% CQ + } \\
1 \% \\
\text { (Dimethylamino)ethyl } \\
\text { methacrylate (DMAEMA) } \\
\text { Resin Base }+1,2.5 \text { or } 5 \mathrm{wt} \\
\% \mathrm{N6} \\
\text { Resin Base }+1,2.5 \text { or } 5 \mathrm{wt} \\
\% \mathrm{CH}\end{array}$ \\
\hline
\end{tabular}


Table 3. Cont

\begin{tabular}{|c|c|c|c|c|c|c|c|c|c|}
\hline Study & $\begin{array}{l}\text { Group } \\
\text { Sample Size }\end{array}$ & $\begin{array}{l}\text { Sample Type or } \\
\text { Measurements }\end{array}$ & $\begin{array}{l}\text { Light } \\
\text { Curing } \\
\text { Time }\end{array}$ & $\begin{array}{l}\text { Assessment } \\
\text { Methods }\end{array}$ & Bacteria & Antibacterial Agents & $\begin{array}{l}\text { Other Tests/Properties } \\
\text { Assessed }\end{array}$ & Control Groups & Tested Groups \\
\hline $\begin{array}{l}\text { Tran et al., } \\
2013 \text { [13] }\end{array}$ & 6 & $7 \mathrm{~mm}$ discs & - & $\begin{array}{c}\text { CFU } \\
\text { Inhibition Zone } \\
\text { (above tests with or without } \\
\text { aging } 2 \text { months in PBS) } \\
\text { CLSM }\end{array}$ & $\begin{array}{l}\text { S. mutans } \\
\text { S. salivarius }\end{array}$ & Organo-selenium & - & $\begin{array}{c}\text { Selenium-free sealant } \\
\text { (BisGMA + TEGDMA + } \\
\text { multifunctional } \\
\text { monomer for } \\
\text { methacrylate formation + } \\
\text { CQ) }\end{array}$ & $\begin{array}{c}0.1 \%, 0.2 \%, 0.25 \%, 0.5 \% \\
\text { or } 1 \% \\
\text { Selenium-containing } \\
\text { dental sealants } \\
\text { (SeLECT-DefenseTM } \\
\text { sealant) }\end{array}$ \\
\hline $\begin{array}{l}\text { Mahapoka } \\
\text { et al., 2012 } \\
\text { [34] }\end{array}$ & 3 & $\begin{array}{c}5 \mathrm{~mm} \text { diameter } \times 2 \\
\text { mm thickness }\end{array}$ & $40 \mathrm{~s}$ & $\begin{array}{c}\text { Inhibition Zone } \\
\text { CFU }\end{array}$ & S. mutans & $\begin{array}{l}\text { Freeze-dried chitosan } \\
\text { Whiskers }\end{array}$ & $\begin{array}{c}\text { DC } \\
\text { Vickers hardness } \\
\text { Depth of cure }\end{array}$ & $\begin{array}{c}\text { Resin Base }=57 \mathrm{wt} \% \\
\text { Bis-GMA + 41.9 wt } \% \\
\text { TEGDMA + } 0.86 \mathrm{wt} \% \\
\text { 2-dimethylaminoethyl } \\
\text { methacrylate + } 0.24 \mathrm{wt} \% \\
\text { CQ } \\
\text { Delton } \\
\text { Teethmate } \\
\text { Seal\&Protect }{ }^{\mathrm{TM}}\end{array}$ & $\begin{array}{c}\text { Resin Base }+1 \mathrm{wt} \% \text { or } \\
1.5 \mathrm{wt} \% \text { or } 2 \mathrm{wt} \% \text { or } 2.5 \\
\text { wt } \% \text { Chitosan }\end{array}$ \\
\hline $\begin{array}{l}\text { Feng Li } \\
\text { et al., } 2011 \\
\text { [35] }\end{array}$ & 5 & $8 \mathrm{~mm}$ diameter & $20 \mathrm{~s}$ & $\begin{array}{c}\text { CFU } \\
\text { (with or without aging for } 6 \\
\text { months in distilled water) } \\
\text { OD }\end{array}$ & S. mutans & $\begin{array}{l}\text { Methacryloxylethyl } \\
\text { cetyl dimethyl } \\
\text { ammonium chloride } \\
\text { (DMAE-CB) }\end{array}$ & $\begin{array}{c}\text { Contact angles } \\
\text { Vickers microhardness } \\
\text { DC } \\
\text { Microleakage }\end{array}$ & $\begin{array}{l}\text { Helioseal } \\
\text { Helioseal F }\end{array}$ & $\begin{array}{c}\text { Helioseal + } 1 \mathrm{w} \% \\
\text { DMAE-CB }\end{array}$ \\
\hline $\begin{array}{l}\text { Kumar } \\
\text { et al., 2010 } \\
{[36]}\end{array}$ & 10 & $\begin{array}{c}5 \mathrm{~mm} \text { diameter } \times 3 \\
\mathrm{~mm} \text { thickness }\end{array}$ & - & Inhibition Zone & S. mutans & Fluoride & - & - & $\begin{array}{l}\text { Glass ionomer cement: } \\
\text { Fuji IX GP } \\
\text { Ketac molar } \\
\text { Pit and fissure sealants: } \\
\text { Teethmate-F1 Helioseal-F }\end{array}$ \\
\hline $\begin{array}{l}\text { Naorungroj } \\
\text { et al., 2010 } \\
\text { [37] }\end{array}$ & $\begin{array}{c}\text { inhibition zone } \\
=4 \\
\mathrm{OD}=9\end{array}$ & $\begin{array}{c}6 \text {-mm sterile paper } \\
\text { disks } \\
6 \mathrm{~mm} \text { diameter } \times 2 \\
\mathrm{~mm} \text { thickness } \\
\text { obtained from labial } \\
\text { surface of lower } \\
\text { anterior bovine teeth }\end{array}$ & $20 \mathrm{~s}$ & $\begin{array}{l}\text { Inhibition Zone (paper disk) } \\
\text { Inhibition Zone (enamel disk) } \\
\text { OD }\end{array}$ & $\begin{array}{l}\text { S. mutans } \\
\text { L. acidophilus }\end{array}$ & Fluoride & - & Blank disks & $\begin{array}{l}\text { Clinpro } \\
\text { Embrace WetBond } \\
\text { UltraSeal XT plus }\end{array}$ \\
\hline $\begin{array}{l}\text { Menon } \\
\text { et al., 2007 } \\
{[38]}\end{array}$ & 15 & $5 \mathrm{~mm}$ diameter & $20 \mathrm{~s}$ & Inhibition Zone & $\begin{array}{l}\text { S. mutans } \\
\text { L. acidophilus }\end{array}$ & Fluoride & - & Helioseal & $\begin{array}{l}\text { Teethmate-F1 } \\
\text { Helioseal-F }\end{array}$ \\
\hline $\begin{array}{l}\text { Matalon } \\
\text { et al., 2003 } \\
{[39]}\end{array}$ & 8 & $4 \mathrm{~mm}$ diameter & - & $\begin{array}{c}\text { Inhibition Zone } \\
\text { OD } \\
\text { (with or without aging for } 2 \\
\text { weeks and } 1 \text { month in PBS) }\end{array}$ & S. mutans & Fluoride & - & Blank wells & $\begin{array}{l}\text { Helioseal F } \\
\text { Ultraseal XT } \\
\text { Conseal F } \\
\text { Dyract Seal }\end{array}$ \\
\hline
\end{tabular}


Table 3. Cont.

\begin{tabular}{|c|c|c|c|c|c|c|c|c|c|}
\hline Study & $\begin{array}{c}\text { Group } \\
\text { Sample Size }\end{array}$ & $\begin{array}{l}\text { Sample Type or } \\
\text { Measurements }\end{array}$ & $\begin{array}{l}\text { Light } \\
\text { Curing } \\
\text { Time }\end{array}$ & $\begin{array}{l}\text { Assessment } \\
\text { Methods }\end{array}$ & Bacteria & Antibacterial Agents & $\begin{array}{l}\text { Other Tests/Properties } \\
\text { Assessed }\end{array}$ & Control Groups & Tested Groups \\
\hline $\begin{array}{l}\text { Loyola- } \\
\text { Rodriguez } \\
\text { et al., } \\
1996 \text { [40] }\end{array}$ & 3 & $3 \mathrm{~mm}$ diameter & - & Inhibition Zone & $\begin{array}{l}\text { S. mutans MT8148, } \\
\text { NG71 and GS5 } \\
\text { (serotype c);S. } \\
\text { mutans MT703R } \\
\text { (serotype e);S. } \\
\text { mutans OMZ175 } \\
\text { (serotype f). S. } \\
\text { sobrinus MT4532, } \\
\text { MT6223 and 6715 } \\
\text { (serotype g). }\end{array}$ & Fluoride & Fluoride release test & Helioseal & $\begin{array}{l}\text { FluoroShieldTM } \\
\text { Teethmate-FTM }\end{array}$ \\
\hline
\end{tabular}

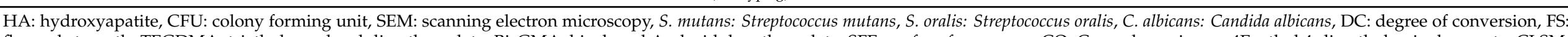

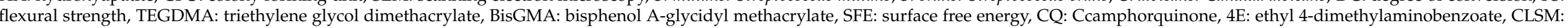

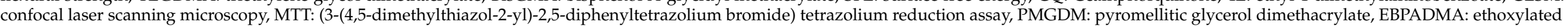

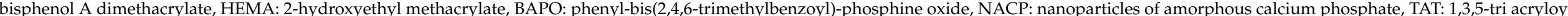

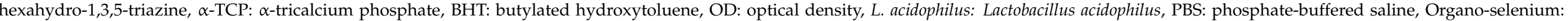
organo-selenium (3-[3-((2-[22]-ethyldiselenyl))-propionyloxy]-butyric acid 2-(2-methyl-acryloyloxy)-ethyl ester). 


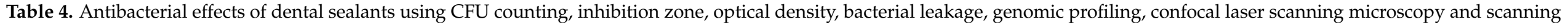
electron microscopy.

\begin{tabular}{|c|c|c|c|c|}
\hline \multicolumn{5}{|c|}{ Antibacterial Effect } \\
\hline $\begin{array}{l}\text { Assessment } \\
\text { Method }\end{array}$ & Study & Intervention (Mean \pm SD) & Control (Mean \pm SD) & Summary of Results \\
\hline \multirow{5}{*}{$\begin{array}{l}\text { CFU } \\
\text { Counting }\end{array}$} & \multirow{2}{*}{$\begin{array}{l}\text { Cocco et al., } \\
2020[10]\end{array}$} & - & \multirow[t]{2}{*}{-} & $\begin{array}{l}\text { Streptococcus mutans: } \\
\text { CFU count for the sealant containing ZnM 5\% showed significant reduction ( } 40 \%) \text { in } \\
\text { comparison to control groups, while ZnM } 2.5 \% \text { did not show significant difference. } \\
\text { Further reductions in the CFU of S. mutans were observed from both SnM } 2.5 \% \text { and } \\
5 \% \text { surfaces }(70 \%) \text { in comparison to control groups }(p>0.05) \text {. }\end{array}$ \\
\hline & & & & $\begin{array}{l}\text { S. oralis and C. albicans: } \\
\text { CFU count for the sealant containing SnM } 5 \% \text { showed a significant reduction in } \\
\text { comparison to control groups }(p>0.05) \text {. }\end{array}$ \\
\hline & $\begin{array}{l}\text { Garcia et al., } \\
2020[11]\end{array}$ & $\begin{array}{c}\text { Biofilm formation }(\log \text { CFU/mL): } \\
\text { Immediate: } \\
2.5 \% \text { METAC } 5.05( \pm 0.13) \\
5 \% \text { METAC } 4.93( \pm 0.25) \\
\text { Long-term: } \\
\text { 2.5\% METAC } 4.98( \pm 0.23) \\
5 \% \text { METAC } 5.02( \pm 0.13) \\
\text { Planktonic bacteria: } \\
\text { Immediate: } \\
\text { 2.5\% METAC } 8.02( \pm 0.14) \\
5 \% \text { METAC } 7.92( \pm 0.21) \\
\text { Long-term: } \\
\text { 2.5\% METAC } 7.95( \pm 0.27) \\
5 \% \text { METAC } 7.86( \pm 0.15)\end{array}$ & $\begin{array}{c}\text { Biofilm formation }(\log \text { CFU/mL): } \\
\text { Immediate: } \\
\text { 0\% METAC } 6.31( \pm 0.10) \\
\text { Negative control }(-) \\
\text { Long-term: } \\
\text { 0\% METAC } 6.26( \pm 0.19) \\
\text { Negative control }(-) \\
\text { Planktonic bacteria: } \\
\text { Immediate: } \\
\text { 0\% METAC } 9.00( \pm 0.17) \\
\text { Negative Control } 9.03( \pm 0.06) \\
\text { Long-term: } \\
\text { 0\% METAC } 9.05( \pm 0.24) \\
\text { Negative control } 9.03( \pm 0.06)\end{array}$ & $\begin{array}{l}\text { There was significant difference between } 2.5 \% \text { or } 5 \% \text { METAC in comparison to } \\
\text { control groups in immediate and long-term CFU count of the form biofilm and } \\
\text { planktonic bacteria. } \\
\text { There was no significant difference between the immediate and long-term CFU } \\
\text { count for each group. }\end{array}$ \\
\hline & $\begin{array}{l}\text { Ibrahim et al., } \\
2020[21]\end{array}$ & - & - & $\begin{array}{l}\text { Overall, the sealants containing } 5 \% \text { DMAHDM }+0 \% \text { NACP showed significant } \\
\text { reductions in CFU count for total microorganisms, total streptococci, lactobacilli and } \\
\text { mutans streptococci in saliva-drived biofilm from both high and low caries-risk } \\
\text { pediatric patients in comparison to the control }(p<0.05) \text {. However, the sealant } \\
\text { containing DMAHDM + NACP showed less reduction in comparison to the sealant } \\
\text { containing only DMAHDM }(p<0.05) \text {. }\end{array}$ \\
\hline & $\begin{array}{l}\text { Monteiro et al., } \\
\quad 2020[12]\end{array}$ & $\begin{array}{c}\text { Biofilm }(\log \text { CFU } / m L) \\
2 \text { wt } \% \alpha-\text { TCP }+2 \text { wt } \% \text { TAT }(4.95 \pm 0.30) \\
\text { Negative control }(-) \\
\text { Planktonic Bacteria (log CFU/mL) } \\
2 \text { wt } \% \alpha \text {-TCP }+2 \text { wt } \% \text { TAT }(7.73 \pm 0.56) \\
\text { Negative control }(-)\end{array}$ & $\begin{array}{c}\text { Biofilm }(\log \text { CFU } / m L) \\
0 \text { wt } \% \alpha-\text { TCP }+0 \text { wt } \% \text { TAT }(6.38 \pm 0.57) \\
\text { Negative control }(-) \\
\text { Planktonic Bacteria }(\log \text { CFU } / \mathrm{mL}) \\
0 \text { wt } \% \alpha \text {-TCP }+0 \text { wt } \% \text { TAT }(9.21 \pm 0.14) \\
\text { Negative control }(9.14 \pm 0.10)\end{array}$ & $\begin{array}{l}\text { The sealant containing } 2 \mathrm{wt} \% \alpha-\mathrm{TCP}+2 \mathrm{wt} \% \text { TAT showed a significant reduction in } \\
\text { CFU counts in comparison to the control group }(p<0.05) \text {. }\end{array}$ \\
\hline
\end{tabular}


Table 4. Cont.

\begin{tabular}{|c|c|c|c|c|}
\hline \multicolumn{5}{|c|}{ Antibacterial Effect } \\
\hline $\begin{array}{l}\text { Assessment } \\
\text { Method }\end{array}$ & Study & Intervention (Mean \pm SD) & Control (Mean \pm SD) & Summary of Results \\
\hline & $\begin{array}{l}\text { Ibrahim et al., } \\
\quad 2019 \text { [27] }\end{array}$ & - & - & $\begin{array}{l}\text { The sealants containing } 5 \% \text { DMAHDM with or without NACP showed significant } \\
\text { reductions in CFU count in comparison to the other sealants }(p<0.05) \text {. }\end{array}$ \\
\hline & $\begin{array}{l}\text { Swetha et al., } \\
\quad 2019 \text { [28] }\end{array}$ & $\begin{array}{c}\text { PFS + 0.5 wt \% ZnO } \\
\text { S. mutans }(8.71 \pm 5.894) \\
\text { L. acidophilus }(7.64 \pm 1.909) \\
\mathbf{P F S}+\mathbf{0 . 5} \mathbf{w t} \% \mathbf{C a F}_{2} \\
\text { S. mutans }(12.21 \pm 2.612) \\
\text { L. acidophilus }(8.50 \pm 4.223) \\
\mathbf{P F S}+\mathbf{0 . 5} \mathbf{w t} \% \mathbf{Z n O}+\mathbf{0 . 5} \mathbf{w t} \% \mathbf{C a F}_{2} \\
\text { S. mutans }(1.50 \pm 1.190) \\
\text { L. acidophilus }(2.43 \pm 0.673) \\
\mathbf{P F S}+\mathbf{1} \mathbf{w t} \% \mathbf{Z n O} \\
\text { S. mutans }(0.93 \pm 0.976) \\
\text { L. acidophilus }(3.21 \pm 1.113) \\
\text { PFS }+\mathbf{1} \mathbf{w t} \% \mathbf{C a F}_{\mathbf{2}} \\
\text { S. mutans }(5.07 \pm 2.244) \\
\text { L. acidophilus }(2.93 \pm 0.886) \\
\text { PFS + } \mathbf{1} \mathbf{w t} \% \mathbf{Z n O}+\mathbf{1} \mathbf{w t} \% \mathbf{C a F}_{2} \\
\text { S. mutans }(0.57 \pm 0.450) \\
\text { L. acidophilus }(0.64 \pm 0.690)\end{array}$ & $\begin{array}{c}\text { Plain PFSs (Control) } \\
\text { S. mutans }(129.29 \pm 26.552) \\
\text { L. acidophilus }(53.07 \pm 7.829)\end{array}$ & $\begin{array}{l}\text { CFU count of all experimental sealants showed statistically significant difference in } \\
\text { comparison to control group }(p<0.001)\end{array}$ \\
\hline & \multirow{2}{*}{ Yu et al., 2016 [30] } & $\begin{array}{c}\text { Colony-forming units (CFU) counts } \\
\text { from S. mutans biofilms on the } \\
\text { material surfaces: } \\
\text { Without aging }(-) \\
\text { With aging }(-) \\
\text { Eco-S Sealant }+\mathbf{4} \mathbf{w t} \% \text { MAE-DB } \\
\text { Without aging }(4.74 \pm 0.97) \times 106 \\
\text { With aging }(4.83 \pm 1.16) \times 106\end{array}$ & $\begin{array}{c}\text { Clinpro }^{\mathrm{TM}} \text { Sealant } \\
\text { Without aging }(6.09 \pm 0.54) \times 108 \\
\text { With aging }(5.8 \pm 0.66) \times 108 \\
\text { Eco-S Sealant } \\
\text { Without aging }(6.43 \pm 0.75) \times 108 \\
\text { With aging }(6.25 \pm 0.66) \times 108\end{array}$ & $\begin{array}{l}\text { The sealant containing } 4 \% \text { MAE-DB showed a significant reduction in CFU count in } \\
\text { comparison to the controls }(p<0.05) \text {. }\end{array}$ \\
\hline & & $\begin{array}{l}\text { Colony forming units (CFU) counts } \\
\text { from S. mutans biofilms in the } \\
\text { material eluents: } \\
\text { Without aging }(-) \\
\text { With aging }(-) \\
\text { Eco-S Sealant }+4 \text { wt } \% \text { MAE-DB } \\
\text { Without aging }(6.45 \pm 0.61) \times 108 \\
\text { With aging }(6.62 \pm 0.47) \times 108\end{array}$ & $\begin{array}{c}\text { Clinpro }^{\mathrm{TM}} \text { Sealant } \\
\text { Without aging }(6.26 \pm 0.46) \times 108 \\
\text { With aging }(6.55 \pm 0.44) \times 108 \\
\text { Eco-S Sealant } \\
\text { Without aging }(6.79 \pm 0.7) \times 108 \\
\text { With aging }(6.84 \pm 0.53) \times 108\end{array}$ & $\begin{array}{l}\text { The sealant containing } 4 \% \text { MAE-DB showed no significant reduction in CFU count in } \\
\text { comparison to the controls. }\end{array}$ \\
\hline
\end{tabular}


Table 4. Cont.

\begin{tabular}{|c|c|c|c|c|}
\hline \multicolumn{5}{|c|}{ Antibacterial Effect } \\
\hline $\begin{array}{l}\text { Assessment } \\
\text { Method }\end{array}$ & Study & Intervention (Mean \pm SD) & Control (Mean \pm SD) & Summary of Results \\
\hline & $\begin{array}{c}\text { Rajabnia et al., } \\
2016[31]\end{array}$ & $\begin{array}{c}\text { (CFU/mL) } \\
\mathbf{2 4} \mathbf{~ h} \\
1 \text { wt \% chitosan (-) } \\
2 \mathrm{wt} \% \text { chitosan } 2443.33 \pm 51.316 \\
3 \mathrm{wt} \% \text { chitosan } 1440.00 \pm 36.056 \\
4 \mathrm{wt} \% \text { chitosan } 871.67 \pm 12.583 \\
5 \mathrm{wt} \% \text { chitosan } 599.33 \pm 9.018 \\
\mathbf{4 8} \mathbf{h} \\
1 \text { wt } \% \text { chitosan }(-) \\
2 \mathrm{wt} \% \text { chitosan } 2523.33 \pm 68.069 \\
3 \mathrm{wt} \% \text { chitosan } 1413.33 \pm 32.146 \\
4 \mathrm{wt} \% \text { chitosan } 836.33 \pm 6.506 \\
5 \mathrm{wt} \% \text { chitosan } 563.67 \pm 12.342 \\
3 \text { months } \\
1 \text { wt \% chitosan }(-) \\
2 \mathrm{wt} \% \text { chitosan } 2020.67 \pm 20.33 \\
3 \mathrm{wt} \% \text { chitosan } 1373.33 \pm 25.166 \\
4 \mathrm{wt} \% \text { chitosan } 782.00 \pm 33.956 \\
5 \mathrm{wt} \% \text { chitosan } 361.67 \pm 17.559 \\
\text { Note: other timepoints were measured } \\
\text { but not reported here. }\end{array}$ & $\begin{array}{c}(\mathrm{CFU} / \mathrm{mL}) \\
0 \mathrm{wt} \% \text { chitosan(-) }\end{array}$ & $\begin{array}{l}\text { The sealants containing } 2,3,4 \text { and } 5 \% \text { of } \mathrm{CH} \text { showed a significant reduction in } \mathrm{CFU} \\
\text { count in } 1 \text { month in comparison to the control and } 1 \% \mathrm{CH} \text { groups }(p<0.001) \text {. In } \\
\text { general, there were significant differences between the groups }(p<0.001) \text {. }\end{array}$ \\
\hline & $\begin{array}{l}\text { Tran et al., } \\
2013 \text { [13] }\end{array}$ & $\begin{array}{c}\text { CFU/sealant disc for } S \text {. salivarius } \\
0.1 \% \text { selenium }(-) \\
1 \% \text { selenium } 0 \\
\text { CFU/sealant disc for } S \text {. } \text { mutans } \\
0.2 \% \text { selenium }(-) \\
0.25 \% \text { selenium } 0 \\
0.5 \% \text { selenium } 0 \\
1 \% \text { selenium } 0 \\
\text { CFU/sealant disc for } S \text {. } \text { mutans after } 2 \\
\text { months aging } \\
0.2 \% \text { selenium - } \\
0.5 \% \text { selenium } 0 \\
1 \% \text { selenium } 0\end{array}$ & $\begin{array}{c}\text { CFU/sealant disc for } S . \text { salivarius } \\
\text { selenium-free sealant } 4 \times 104 \\
\text { CFU/sealant disc for } S . \text { mutans } \\
\text { selenium-free sealant } 2 \times 105 \\
\\
\text { CFU/sealant disc for } S . \text { mutans after } 2 \\
\text { months aging } \\
0.2 \% \text { selenium - } \\
0.5 \% \text { selenium - } \\
1 \% \text { selenium - }\end{array}$ & $\begin{array}{l}\text { The } 1 \% \text { Se containing sealant completely inhibited the growth of } S . \text { salivarius } \\
(p<0.05) \text { in comparison to the other groups. } \\
\text { The } 0.25 \%, 0.5 \% \text { and } 1 \% \text { Se containing sealants completely inhibited the growth of } S . \\
\text { mutans }(p<0.05) \text { in comparison to the other groups, and } 2 \text { months aging in PBS } 0.5 \% \\
\text { and } 1 \% \text { Se containing sealants completely inhibited the growth of S. mutans }(p<0.05) \\
\text { in comparison to the other groups. }\end{array}$ \\
\hline
\end{tabular}


Table 4. Cont.

\begin{tabular}{|c|c|c|c|c|}
\hline \multicolumn{5}{|c|}{ Antibacterial Effect } \\
\hline $\begin{array}{l}\text { Assessment } \\
\text { Method }\end{array}$ & Study & Intervention (Mean \pm SD) & Control (Mean \pm SD) & Summary of Results \\
\hline & $\begin{array}{c}\text { Mahapoka et al., } \\
2012 \text { [34] }\end{array}$ & $\begin{array}{c}\text { Bacterial reduction }(\%) \\
(\text { BRR })=[(\mathbf{N} 1-\mathbf{N} 2) / \mathbf{N} 1] \times \mathbf{1 0 0} \\
\text { Where } \mathbf{N} 1 \text { and } \mathbf{N} \mathbf{2}=\text { viable count at } \\
\mathbf{0} \text { and } \mathbf{1 2} \mathbf{h} . \\
1 \% \text { chitosan } 31.2(4.7) \\
1.5 \% \text { chitosan } 39.2(3.7) \\
2 \% \text { chitosan } 72.2(0.6) \\
2.5 \% \text { chitosan } 75.9(0.6)\end{array}$ & $\begin{array}{c}\text { Bacterial reduction }(\%) \\
(\text { BRR })=[(\mathbf{N} 1-\mathbf{N} 2) / \mathbf{N} 1] \times \mathbf{1 0 0} \\
\text { Where } \mathbf{N} 1 \text { and } \mathbf{N 2}=\text { viable count at } \\
\mathbf{0} \text { and } \mathbf{1 2} \mathbf{h} . \\
\text { Resin base } 13.7(2.9) \\
\text { Delton }{ }^{\circledR} 25.9(3.8) \\
\text { Seal\&Protect }{ }^{\mathrm{TM}} 83.1(0.7) \\
\text { Teethmate }^{\mathrm{TM}} \mathrm{F}-176.9(0.3)\end{array}$ & $\begin{array}{l}\text { The } 2 \%, 2.5 \% \text { chitosan, Teethmate } \\
\text { significantly higher bacterial reeducation rate in comparison to the other groups } \\
(p<0.05) \text {. } \\
\text { Seal\&Protect showed the highest bacterial reeducation rate. }\end{array}$ \\
\hline & $\begin{array}{l}\text { Feng Li et al., } \\
2011 \text { [35] }\end{array}$ & - & - & $\begin{array}{l}\text { The 1\% DMAE-CB sealant showed a significant reduction in CFU count in } \\
\text { comparison to the controls with or without aging }(p<0.05) \text {. There was no significant } \\
\text { difference between the aged and non-aged samples in each group }(p>0.05) \text {. }\end{array}$ \\
\hline $\begin{array}{l}\text { Inhibition } \\
\text { Zone }\end{array}$ & $\begin{array}{l}\text { Shanmugaavel } \\
\text { et al., 2015 [32] }\end{array}$ & $\begin{array}{c}\text { Inhibition zone (mm) } \\
\text { S. mutans } \\
\text { 0 day } \\
\text { GIS }+1 \% \text { CHX } 10.36 \mathrm{~mm} \\
\text { Clinpro }+1 \% \text { CHX } 14.82 \\
7 \text { days } \\
\text { GIS }+1 \% \text { CHX } 5.7 \mathrm{~mm} \\
\text { Clinpro }+1 \% \text { CHX } 8.68 \\
30 \text { days } \\
\text { GIS }+1 \% \text { CHX } 1.67 \mathrm{~mm} \\
\text { Clinpro }+1 \% \text { CHX } 5.83 \mathrm{~mm} \\
\text { L. acidophilus } \\
\text { 0 day } \\
\text { GIS }+1 \% \text { CHX } 9.7 \mathrm{~mm} \\
\text { Clinpro + } 1 \% \text { CHX } 10.18 \mathrm{~mm} \\
7 \text { days } \\
\text { GIS }+1 \% \text { CHX } 5.02 \mathrm{~mm} \\
\text { Clinpro }+1 \% \text { CHX } 8.16 \mathrm{~mm} \\
30 \text { days } \\
\text { GIS }+1 \% \text { CHX } 1.5 \mathrm{~mm} \\
\text { Clinpro }+1 \% \text { CHX } 4.83 \mathrm{~mm}\end{array}$ & $\begin{array}{c}\text { Inhibition zone (mm) } \\
\text { S. mutans } \\
\text { 0 day } \\
\text { GIS } 7.28 \mathrm{~mm} \\
\text { Clinpro } 11.96 \mathrm{~mm} \\
\mathbf{7} \text { days } \\
\text { GIS } 0 \mathrm{~mm} \\
\text { Clinpro } 0 \mathrm{~mm} \\
\mathbf{3 0} \text { days } \\
\text { GIS } 0 \mathrm{~mm} \\
\text { Clinpro } 0 \mathrm{~mm} \\
\text { L. acidophilus } \\
\mathbf{0} \text { day } \\
\text { GIS } 4.16 \mathrm{~mm} \\
\text { Clinpro } 4.4 \mathrm{~mm} \\
\mathbf{7} \text { days } \\
\text { GIS } 0 \mathrm{~mm} \\
\text { Clinpro } 0 \mathrm{~mm} \\
\mathbf{3 0} \text { days } \\
\text { GIS } 0 \mathrm{~mm} \\
\text { Clinpro } 0 \mathrm{~mm}\end{array}$ & $\begin{array}{l}\text { The sealants containing } 1 \% \mathrm{CHX} \text { showed significant increase in the inhibition zones } \\
\text { against } S \text {. mutans and L. acidophilus at } 0 \text { day in comparison to the controls. These } \\
\text { differences were still observed after } 7 \text { and } 30 \text { days but less pronounced }(p<0.05) \text {. }\end{array}$ \\
\hline
\end{tabular}


Table 4. Cont.

\begin{tabular}{|c|c|c|c|c|}
\hline \multicolumn{5}{|c|}{ Antibacterial Effect } \\
\hline $\begin{array}{l}\text { Assessment } \\
\text { Method }\end{array}$ & Study & Intervention (Mean \pm SD) & Control (Mean \pm SD) & Summary of Results \\
\hline & $\begin{array}{l}\text { Hamilton et al., } \\
2014 \text { [33] }\end{array}$ & - & - & $\begin{array}{l}\text { The } 0.12 \% \mathrm{CHX} \text { solution was the only group that showed an inhibition zone }(4 \mathrm{~mm}) \\
\text { for S. mutans at } 24,48 \text { and } 120 \mathrm{~h} \text {. There was no inhibition zone for all } \\
\text { experimental groups. } \\
\text { Only the positive control, that is, chlorhexidine } 0.12 \% \text { solution demonstrated an } \\
\text { inhibition zone }(4 \mathrm{~mm}) \text { against } \mathrm{S} \text {. mutans during the time of the study }(24,48 \text { and } \\
120 \mathrm{~h}) \text {. No inhibition zone was observed in any of the experimental groups tested } \\
\text { (data not shown). }\end{array}$ \\
\hline & $\begin{array}{l}\text { Mahapoka et al., } \\
2012 \text { [34] }\end{array}$ & $\begin{array}{l}\text { Width of inhibition zone }(\mathbf{m m}) \\
2.5 \% \text { chitosan whisker }(10.7 \pm 0.3) \\
2 \% \text { chitosan whisker }(10.1 \pm 0.2) \\
1.5 \% \text { chitosan whisker }(5.0 \pm 0) \\
1 \% \text { chitosan whisker }(5.0 \pm 0)\end{array}$ & $\begin{array}{c}\text { Width of inhibition zone (mm) } \\
\text { Control }(5.0 \pm 0) \\
\text { Delton }{ }^{\circledR}(5.0 \pm 0) \\
\text { Seal\&Protect }{ }^{\mathrm{TM}}(15.2 \pm 0.2) \\
\text { Teethmate }{ }^{\mathrm{TM}} \mathrm{F}-1(11.4 \pm 0.2)\end{array}$ & $\begin{array}{l}\text { The } 2 \%, 2.5 \% \text { chitosan, Teethmate }{ }^{\mathrm{TM}} \mathrm{F}-1 \text { and Seal\&Protect }{ }^{\mathrm{TM}} \text { sealants showed a } \\
\text { higher inhibition zone in comparison to the other groups. } \\
\text { Seal\&Protect showed the highest bacterial reeducation rate. }\end{array}$ \\
\hline & $\begin{array}{c}\text { Kumar et al., } 2010 \\
\text { [36] }\end{array}$ & $\begin{array}{l}\text { Width of inhibition zone }(\mathbf{m m}) \\
\text { Ketac molar }(2.18 \pm 0.24) \\
\text { Fuji IX GP }(5.50 \pm 0.62) \\
\text { Teethmate-F1 }(8.43 \pm 0.42) \\
\text { Helioseal-F }(0.00 \pm 0.00)\end{array}$ & - & $\begin{array}{l}\text { The Teethmate-F1 sealant showed the largest inhibition zone while the Helioseal-F } \\
\text { sealant showed no inhibition zone }(p=00) \text {. } \\
\text { Seal\&Protect showed the highest inhibition zone. }\end{array}$ \\
\hline & $\begin{array}{l}\text { Naorungroj et al., } \\
2010[37]\end{array}$ & $\begin{array}{c}\text { Inhibition zone in mm (paper disk) } \\
\text { L. acidophilus } \\
\text { Clinpro }(17.6 \pm 2.8) \\
\text { Embrace }(6.0 \pm 0.0) \\
\text { UltraSeal }(6.0 \pm 0.0) \\
\text { S. mutans } \\
\text { Clinpro }(6.8 \pm 0.5) \\
\text { Embrace }(7.9 \pm 1.3) \\
\text { UltraSeal }(6.0 \pm 0.0) \\
\text { Inhibition zone in mm (enamel disk) } \\
\text { L. acidophilus } \\
\text { Clinpro }(9.8 \pm 0.3) \\
\text { Embrace }<6.0 \\
\text { UltraSeal }(6.0 \pm 0.0) \\
\text { S. mutans } \\
\text { Clinpro }(6.0 \pm 0.0) \\
\text { Embrace }(6.5 \pm 0.0)\end{array}$ & $\begin{array}{l}\text { Inhibition zone in mm (paper disk) } \\
\text { L. acidophilus and S. mutans } \\
\text { Control }(0.0 \pm 0.0)\end{array}$ & $\begin{array}{l}\text { The Clinpro sealant showed the largest inhibition zone against L. acidophilus. } \\
\text { The Embrace sealant showed an inhibition zone against S. mutans using both paper } \\
\text { and enamel disk (note: no } p \text {-value was given). }\end{array}$ \\
\hline
\end{tabular}


Table 4. Cont.

\begin{tabular}{|c|c|c|c|c|}
\hline \multicolumn{5}{|c|}{ Antibacterial Effect } \\
\hline $\begin{array}{l}\text { Assessment } \\
\text { Method }\end{array}$ & Study & Intervention (Mean \pm SD) & Control (Mean \pm SD) & Summary of Results \\
\hline & $\begin{array}{l}\text { Menon et al., } \\
2007[38]\end{array}$ & $\begin{array}{c}\text { Inhibition zone in mm } \\
\text { S. mutans } \\
\text { Teethmate-F1 (11.763 } \pm 0.391) \\
\text { Helioseal-F } 0 \\
\text { L. acidophilus } \\
\text { Teethmate-F1 (13.583 } \pm 0.318) \\
\text { Helioseal-F } 0\end{array}$ & $\begin{array}{c}\text { Inhibition zone in } \mathbf{m m} \\
\text { S. mutans } \\
\text { Helioseal } 0 \\
- \\
\text { L. acidophilus } \\
\text { Helioseal } 0 \\
-\end{array}$ & $\begin{array}{l}\text { The Teethmate-F1 showed a significant difference in the inhibition zone between } \\
\text { S. mutans and L. acidophilus. }\end{array}$ \\
\hline & $\begin{array}{c}\text { Loyola- } \\
\text { Rodriguez et al., } \\
1996 \text { [40] }\end{array}$ & $\begin{array}{c}\text { Width of inhibition zone (mm) } \\
\text { S. mutans } \\
\text { MT8148 } \\
\text { Teethmate-FTM }(1.0 \pm 0.0) \\
\text { FluoroShieldTM }(0 \pm 0) \\
\text { NG71 } \\
\text { Teethmate-FTM }(1.0 \pm 0.0) \\
\text { FluoroShieldTM }(0 \pm 0) \\
\text { GS5 } \\
\text { Teethmate-FTM }(1.0 \pm 0.0) \\
\text { FluoroShieldTM }(0 \pm 0) \\
\text { MT703R } \\
\text { Teethmate-FTM }(0.6 \pm 0.3) \\
\text { FluoroShieldTM }(0 \pm 0) \\
\text { OMZ175 } \\
\text { Teethmate-FTM }(0.6 \pm 0.3) \\
\text { FluoroShieldTM }(0 \pm 0) \\
\text { S. sobrinus } \\
\text { 6715 } \\
\text { Teethmate-FTM }(1.0 \pm 0.3) \\
\text { FluoroShieldTM }(0 \pm 0) \\
\text { MT4532 } \\
\text { Teethmate-FTM }(0.6 \pm 0.3) \\
\text { FluoroShieldTM }(0 \pm 0) \\
\text { MT6223 } \\
\text { Teethmate-FTM }(1.0 \pm 0.0) \\
\text { FluoroShieldTM }(0 \pm 0)\end{array}$ & $\begin{array}{c}\text { Width of inhibition zone (mm) } \\
\text { S. mutans } \\
\text { MT8148 } \\
\text { Helioseal }(0 \pm 0) \\
- \\
\text { NG71 } \\
\text { Helioseal }(0 \pm 0) \\
- \\
\text { GS5 } \\
\text { Helioseal }(0 \pm 0) \\
\text { MT703R } \\
\text { Helioseal }(0 \pm 0) \\
- \\
\text { OMZ175 } \\
\text { Helioseal }(0 \pm 0) \\
- \\
\text { S. sobrinus } \\
\mathbf{6 7 1 5} \\
\text { Helioseal }(0 \pm 0) \\
- \\
\text { MT4532 } \\
\text { Helioseal }(0 \pm 0) \\
- \\
\text { MT6223 } \\
\text { Helioseal }(0 \pm 0) \\
-\end{array}$ & $\begin{array}{l}\text { The Teethmate-F sealant was the only material that showed an inhibition zone } \\
\text { against all strains of } S \text {. mutans. }\end{array}$ \\
\hline
\end{tabular}


Table 4. Cont.

\begin{tabular}{|c|c|c|c|c|}
\hline \multicolumn{5}{|c|}{ Antibacterial Effect } \\
\hline $\begin{array}{l}\text { Assessment } \\
\text { Method }\end{array}$ & Study & Intervention (Mean \pm SD) & Control (Mean \pm SD) & Summary of Results \\
\hline & $\begin{array}{l}\text { Feng Li et al., } \\
2011[35]\end{array}$ & - & - & There were no significant differences between the groups $(p>0.05)$. \\
\hline $\begin{array}{l}\text { Optical } \\
\text { Density }\end{array}$ & $\begin{array}{l}\text { Naorungroj et al., } \\
\quad 2010[37]\end{array}$ & $\begin{array}{l}\text { L. acidophilus suspensions exposed to } \\
\text { pit and fissure sealants. } \\
\text { No wash } \\
\text { Clinpro }(0.075 \pm 0.010) \\
\text { Embrace }(0.140 \pm 0.029) \\
\text { UltraSeal }(0.056 \pm 0.002) \\
\text { 30-min wash } \\
\text { Clinpro }(0.075 \pm 0.005) \\
\text { Embrace }(0.086 \pm 0.005) \\
\text { UltraSeal }(0.086 \pm 0.003) \\
\text { 24-h wash } \\
\text { Clinpro }(0.077 \pm 0.003) \\
\text { Embrace }(0.098 \pm 0.029) \\
\text { UltraSeal }(0.067 \pm 0.005) \\
\text { 48-h wash } \\
\text { Clinpro }(0.103 \pm 0.026) \\
\text { Embrace }(0.098 \pm 0.065) \\
\text { UltraSeal }(0.106 \pm 0.026) \\
\text { S. mutans suspensions exposed to pit } \\
\text { and fissure sealants. } \\
\text { No wash } \\
\text { Clinpro }(0.068 \pm 0.007) \\
\text { Embrace }(0.117 \pm 0.018) \\
\text { UltraSeal }(0.051 \pm 0.002) \\
\text { 30-min wash } \\
\text { Clinpro }(0.073 \pm 0.005) \\
\text { Embrace }(0.088 \pm 0.008) \\
\text { UltraSeal }(0.066 \pm 0.001) \\
\mathbf{2 4 - h} \text { wash } \\
\text { Clinpro }(0.053 \pm 0.003) \\
\text { Embrace }(0.054 \pm 0.003) \\
\text { UltraSeal }(0.341 \pm 0.044) \\
\mathbf{4 8 - h} \text { wash } \\
\text { Clinpro }(0.113 \pm 0.028) \\
\text { Embrace }(0.054 \pm 0.004) \\
\text { UltraSeal }(0.433 \pm 0.026)\end{array}$ & $\begin{array}{c}\text { L. acidophilus suspensions exposed to pit } \\
\text { and fissure sealants } \\
\text { No wash } \\
\text { Control (0.455 } \pm 0.019) \\
- \\
- \\
30 \text {-min wash } \\
\text { Control (0.431 } \pm 0.014) \\
- \\
- \\
24-h \text { wash } \\
\text { Control (0.429 } \pm \text { 0.017) } \\
- \\
- \\
48-h \text { wash } \\
\text { Control (0.405 } \pm 0.012) \\
- \\
- \\
\text { S. mutans suspensions exposed to pit and } \\
\text { fissure sealants } \\
\text { No wash } \\
\text { Control (0.441 } \pm 0.024) \\
- \\
- \\
30-\text { min wash } \\
\text { Control (0.557 } \pm 0.060) \\
- \\
- \\
24-h \text { wash } \\
\text { Control (0.423 } \pm 0.019) \\
- \\
- \\
48-h \text { wash } \\
\text { Control (0.398 } \pm 0.021) \\
- \\
-\end{array}$ & No statistical analysis was mentioned in this study. \\
\hline
\end{tabular}


Table 4. Cont.

\begin{tabular}{|c|c|c|c|c|}
\hline \multicolumn{5}{|c|}{ Antibacterial Effect } \\
\hline $\begin{array}{l}\text { Assessment } \\
\text { Method }\end{array}$ & Study & Intervention (Mean \pm SD) & Control (Mean \pm SD) & Summary of Results \\
\hline & $\begin{array}{l}\text { Matalon et al., } \\
2003[39]\end{array}$ & $\begin{array}{c}\text { Fresh material } \\
\text { Conseal F }(2.659 \pm 0.401) \\
\text { Helioseal F }(1.859 \pm 0.2288) \\
\text { Ultraseal XT }(0.9250 \pm 0.9547) \\
\text { Dyract Seal }(0.07714 \pm 0.1459) \\
\text { Aged two weeks } \\
\text { Conseal F }(2.915 \pm 0.06325) \\
\text { Helioseal F }(3.140 \pm 0.1963) \\
\text { Ultraseal XT }(2.327 \pm 0.197) \\
\text { Dyract Seal }(0.1025 \pm 0.00276) \\
\text { Aged one month } \\
\text { Conseal F }(3.149 \pm 0.307) \\
\text { Helioseal F }(3.835 \pm 0.1181) \\
\text { Ultraseal XT }(2.914 \pm 0.1369) \\
\text { Dyract Seal }(2.880 \pm 0.2658) \\
\end{array}$ & $\begin{array}{c}\text { Fresh material } \\
\text { Control }(2.872 \pm 0.4981) \\
- \\
- \\
- \\
\text { Aged two weeks } \\
\text { Control }(3.165 \pm 0.3695) \\
- \\
- \\
- \\
\text { Aged one month } \\
\text { Control }(2.888 \pm 0.2604) \\
- \\
- \\
- \\
\end{array}$ & $\begin{array}{l}\text { The Dyract Seal showed the highest antibacterial affect in comparison to other } \\
\text { groups; this difference was significant at } 0 \text { timepoint and for 2-week aged samples } \\
\text { but not the 1-month aged samples }(p<0.0001) \text {. }\end{array}$ \\
\hline $\begin{array}{l}\text { Bacterial } \\
\text { Leakage } \\
\text { Testing }\end{array}$ & $\begin{array}{l}\text { Zmener et al., } \\
2019[29]\end{array}$ & $\begin{array}{c}\text { Leakage frequency after } 90 \text { days }(n) \\
\text { EWBMCP } 4 \text { out of } 10 \\
-\end{array}$ & $\begin{array}{l}\text { Leakage frequency after } 90 \text { days }(n) \\
\text { EWB } 6 \text { out of } 9 \\
\text { CLPR } 5 \text { out of } 10\end{array}$ & $\begin{array}{l}\text { For the leakage frequency there was no significant difference between EWBMCP and } \\
\text { CLPR sealants }(p>0.05) \text {. However, both showed a significant difference in leakage } \\
\text { frequency in comparison to EWB sealant }(p<0.05) \text {. } \\
\text { The EWBMCP sealant showed a higher median survival time in comparison to the } \\
\text { other sealants. }\end{array}$ \\
\hline $\begin{array}{l}\text { Genomic } \\
\text { Profiling }\end{array}$ & $\begin{array}{l}\text { Tbrahim et al., } \\
\quad 2020[21]\end{array}$ & - & - & $\begin{array}{l}\text { The sealant containing DMAHDM + NACP showed reduction of the relative } \\
\text { abundances of the } 16 \mathrm{~S} \text { rRNA at the genus level of Streptococcus for both types of } \\
\text { inoculum. }\end{array}$ \\
\hline \multirow{3}{*}{$\begin{array}{l}\text { Confocal } \\
\text { Laser } \\
\text { Scanning } \\
\text { Microscopy } \\
\text { (CLSM) }\end{array}$} & $\begin{array}{l}\text { Ibrahim et al., } \\
\quad 2020[21]\end{array}$ & - & - & $\begin{array}{l}\text { The sealant containing DMAHDM + NACP showed substantial reduction in the } \\
\text { formation, distribution and development of the biofilm in both high and low } \\
\text { caries-risk pediatric patients in comparison to the control group. }\end{array}$ \\
\hline & $\begin{array}{l}\text { Ibrahim et al., } \\
\quad 2019[27]\end{array}$ & - & - & $\begin{array}{l}\text { The sealant containing } 5 \% \text { DMAHDM + } 20 \% \text { NACP showed reduction in visible } \\
\text { biofilm biomass in comparison to the experimental control, which showed denser } \\
\text { and thicker biofilm. }\end{array}$ \\
\hline & Yu et al., 2016 [30] & - & - & $\begin{array}{l}\text { The sealant containing } 4 \% \text { MAE-DB showed lower density of cells and greater } \\
\text { proportions of dead bacteria in comparison to the controls. }\end{array}$ \\
\hline
\end{tabular}


Table 4. Cont.

\begin{tabular}{|c|c|c|c|c|}
\hline \multicolumn{5}{|c|}{ Antibacterial Effect } \\
\hline $\begin{array}{l}\text { Assessment } \\
\text { Method }\end{array}$ & Study & Intervention (Mean $\pm \mathrm{SD}$ ) & Control (Mean \pm SD) & Summary of Results \\
\hline & $\begin{array}{l}\text { Tran et al., } \\
2013[13]\end{array}$ & $\begin{array}{l}\text { For } S \text {. mutans } \\
0.25 \% \text { selenium } \\
\text { Biomass 0 } \\
\text { average thickness } 0 \\
\text { surface area 0 }\end{array}$ & $\begin{array}{c}\text { For } S . \text { mutans } \\
\text { selenium-free sealant } \\
\text { Biomass } 315 \mu \mathrm{m}^{3} / \mu \mathrm{m}^{2} \\
\text { average thickness } 429 \mu \mathrm{m} \\
\text { surface area } 47 \times 106 \mu \mathrm{m}^{2}\end{array}$ & The $0.25 \%$ containing Se sealant did not show in growth in comparison to the control. \\
\hline $\begin{array}{l}\text { Scanning } \\
\text { Electron }\end{array}$ & $\begin{array}{l}\text { Cocco et al., } \\
2020[10]\end{array}$ & - & - & $\begin{array}{l}\text { The SnM 5\% containing sealant showed reduction in the biofilm total biomass with } \\
\text { minimum amount of exopolysaccharides (EPS) in comparison to the control groups. }\end{array}$ \\
\hline $\begin{array}{l}\text { Microscopy } \\
\quad(\text { SEM) }\end{array}$ & $\begin{array}{l}\text { Hamilton et al., } \\
2014[33]\end{array}$ & - & - & $\begin{array}{l}\text { There was not a significant difference between } \mathrm{N} 6 \text { and } \mathrm{CH} \text { fiber diameter } \\
(p=0.0601) \text {. }\end{array}$ \\
\hline
\end{tabular}

Table 5. Antibacterial effects of dental sealants measuring the metabolic activity, lactic acid production, pH, polysaccharide production and acid stress and oxygen stress tolerance.

\begin{tabular}{|c|c|c|c|c|}
\hline \multicolumn{5}{|c|}{ Antibacterial Effect } \\
\hline Assessment & Study & Intervention (Mean \pm SD) & Control (Mean \pm SD) & Summary of Results \\
\hline \multirow{2}{*}{$\begin{array}{l}\text { Metabolic } \\
\text { Activity }\end{array}$} & $\begin{array}{l}\text { Ibrahim et al., } \\
\quad 2020[21]\end{array}$ & - & - & $\begin{array}{l}\text { The sealants containing } 5 \% \text { DMAHDM }+0 \% \text { NACP showed significant reductions in metabolic activity in } \\
\text { saliva-derived biofilm from both high and low caries-risk pediatric patients in comparison to the control } \\
(p<0.05) \text {. However, the sealant containing DMAHDM }+ \text { NACP showed less reduction in comparison to the } \\
\text { sealant containing only DMAHDM }(p<0.05) \text {. There was no significant difference in the same group regarding } \\
\text { the type of the saliva inoculum }(p>0.05) \text {. }\end{array}$ \\
\hline & $\begin{array}{l}\text { Ibrahim et al., } \\
\quad 2019 \text { [27] }\end{array}$ & - & - & $\begin{array}{l}\text { The sealants containing } 5 \% \text { DMAHDM with or without NACP showed significant reductions }(82-87 \%) \text { in } \\
\text { metabolic activity in comparison to the other sealants }(p<0.05) \text {. }\end{array}$ \\
\hline \multirow{2}{*}{$\begin{array}{l}\text { Lactic Acid } \\
\text { Production }\end{array}$} & $\begin{array}{l}\text { Ibrahim et al., } \\
\quad 2020[21]\end{array}$ & - & - & $\begin{array}{l}\text { The sealant containing DMAHDM + NACP showed reduction of the relative abundances of the 16S rRNA at } \\
\text { the genus level of Streptococcus for both types of inoculum. }\end{array}$ \\
\hline & $\begin{array}{l}\text { Ibrahim et al., } \\
\quad 2019 \text { [27] }\end{array}$ & - & - & $\begin{array}{l}\text { The sealants containing } 5 \% \text { DMAHDM with or without NACP showed significant reduction in lactic acid } \\
\text { production in comparison to the other sealants }(p<0.05) \text {. }\end{array}$ \\
\hline
\end{tabular}


Table 5. Cont.

\begin{tabular}{|c|c|c|c|c|}
\hline \multicolumn{5}{|c|}{ Antibacterial Effect } \\
\hline Assessment & Study & Intervention (Mean \pm SD) & Control (Mean \pm SD) & Summary of Results \\
\hline \multirow{5}{*}{$\mathrm{pH}$} & \multirow{4}{*}{$\begin{array}{l}\text { Coco et al., } \\
2020[10]\end{array}$} & $\begin{array}{l}\text { S. mutans } \\
2.5 \% \mathrm{ZnM}(4.6 \pm 0.0) \\
5 \% \mathrm{ZnM}(4.7 \pm 0.1) \\
2.5 \% \mathrm{SnM}(5.4 \pm 0.1) \\
5 \% \mathrm{SnM}(6.7 \pm 1.0)\end{array}$ & $\begin{array}{c}\text { S. mutans } \\
\text { Control }(4.5 \pm 0.0) \\
\quad- \\
- \\
-\end{array}$ & \multirow{4}{*}{$\begin{array}{l}\text { There was no significant difference between the } \mathrm{pH} \text { of the biofilm cultured on the sealants containing } 2.5 \% \\
\text { and } 5 \% \mathrm{ZnM} \text { in comparison to the control group. } \\
\text { There was a slight significant difference between } 2.5 \% \text { SnM and the control group } \\
\text { The } 5 \% \text { SnM containing sealant kept the } \mathrm{pH} \text { level close to the neutral. }\end{array}$} \\
\hline & & $\begin{array}{l}\text { S. oralis } \\
2.5 \% \mathrm{ZnM}- \\
5 \% \mathrm{ZnM}- \\
2.5 \% \mathrm{SnM}- \\
5 \% \mathrm{SnM}(6.5 \pm 0.4)\end{array}$ & $\begin{array}{l}\text { S. oralis } \\
\text { Control }(5.7 \pm 0.9) \\
\quad- \\
\quad- \\
-\end{array}$ & \\
\hline & & $\begin{array}{l}\text { C. albicans } \\
2.5 \% \mathrm{ZnM}- \\
5 \% \mathrm{ZnM}- \\
2.5 \% \mathrm{SnM}- \\
5 \% \mathrm{SnM}(6.8 \pm 0.1)\end{array}$ & $\begin{array}{l}\text { C. albicans } \\
\text { Control }(6.8 \pm 0.1) \\
\quad- \\
\quad- \\
\quad-\end{array}$ & \\
\hline & & $\begin{array}{l}\text { S. mutansandC. albicans } \\
2.5 \% \mathrm{ZnM}- \\
5 \% \mathrm{ZnM}- \\
2.5 \% \mathrm{SnM}- \\
5 \% \mathrm{SnM}(6.6 \pm 0.3)\end{array}$ & $\begin{array}{l}\text { S. mutansand C. albicans } \\
\text { Control (4.4 } \pm 0.1) \\
- \\
- \\
-\end{array}$ & \\
\hline & $\begin{array}{l}\text { Ibrahim et al., } \\
\quad 2019[27]\end{array}$ & - & - & $\begin{array}{l}\text { There was a significant difference between the } \mathrm{pH} \text { of the NACP-containing groups in comparison to the other } \\
\text { groups at 8-h time point }(p<0.05) \text {. } \\
\text { The NACP-containing groups kept the } \mathrm{pH} \text { level close to neutral } \mathrm{pH} \text { at all time points. }\end{array}$ \\
\hline $\begin{array}{l}\text { Poly-saccharide } \\
\text { Production }\end{array}$ & $\begin{array}{l}\text { Ibrahim et al., } \\
2019[27]\end{array}$ & - & - & $\begin{array}{l}\text { The sealants containing } 5 \% \text { DMAHDM with or without NACP showed significant reduction in } \\
\text { polysaccharide production in comparison to the other sealants }(p<0.05) \text {. }\end{array}$ \\
\hline $\begin{array}{l}\text { Acid Stress and } \\
\text { Oxygen Stress } \\
\text { Tolerance }\end{array}$ & $\begin{array}{l}\text { Ibrahim et al., } \\
\quad 2019[27]\end{array}$ & - & - & $\begin{array}{l}\text { The sealants containing } 5 \% \text { DMAHDM showed a lower survival rate at } 10 \mathrm{~min}(38-44 \%) \text { in comparison to the } \\
\text { control and NACP only groups }(60-65 \%) \text { after exposure to } \mathrm{pH} 2.8 \text {. There was no pronounced difference } \\
\text { between the groups at the later time points. } \\
\text { The sealants containing } 5 \% \text { DMAHDM showed a lower survival rate at } 10 \text { and } 20 \text { min but not at } 30 \text { and } 45 \\
\text { min in comparison to the other groups after exposure to } 0.2 \% \mathrm{H}_{2} \mathrm{O}_{2} \text {. }\end{array}$ \\
\hline
\end{tabular}




\section{Discussion}

The incorporation of antibacterial agents into dental sealants has sought to develop resins with improved therapeutic properties to prevent dental caries. The present review mapped the studies that evaluated dental sealants containing antibacterial agents. This review's findings evidenced how researchers have been assessing dental sealants and summarized the outcomes of the previous studies. Furthermore, this review summarized the main compounds that have been tested as antibacterial agents in dental sealants and evaluated the quality of the current evidence.

From the nineteen studies included in this systematic review, most of them (thirteen) showed a medium risk of bias. This finding was mainly based on the fact that the sample calculation and blinding were not included in all of them. It is common to observe that researchers consider previous studies to define the sample size, without critical thinking or indication of the sample calculation. This is a problem, especially when no statistically significant differences are detected in the test. The authors must be aware that a small sample size can decrease the statistical power and result in type II error. As the statistical power is not always reported, it is suggested that the sample size calculation and the power of the study are written in the manuscripts about this subject to improve the quality of research reports. Blinding is another parameter that is commonly not followed up [26]. The addition of antibacterial agents in dental resins frequently alters their physical properties, such as the color and viscosity of dental sealants. These characteristics can hinder the blinding process. As well as the reporting of sample size calculation, this parameter could assist in increasing the quality of studies.

The methods for analyzing the antibacterial activity of restorative materials have been criticized in the literature [26,41,42]. This stems from the lack of standardization of the tests, the misinterpretation of purely qualitative analyses or the misuse of quantitative tests. The methods addressed to analyze the dental sealants involved different outcomes. A meta-analysis was not performed due to the methodological variations, which should be more standardized to produce comparable data. Fortunately, all included studies used at least one quantitative test. In addition, the CFU counting test, which is the gold standard for evaluating microorganisms' viability, was the most used. The inhibition zone test was the second most used. For some years now, some journals have been asking that authors not use this method.

A clear example of this was a publication by the Editorial Board of the Journal of Endodontics in 2007 [43]. The editors argued that this journal would no longer accept inhibition zone tests because antimicrobial agents can interact with the agar medium and remove ions from the environment. Furthermore, the agar medium's buffering activity and the chemical interaction between the agar and the antibacterial agents can change the inhibition zone diameter and, consequently, the conclusions about the antibacterial effect. In addition, the zone of inhibition depends on the agent's ability to permeate through the agar, which is essentially hydrophilic. Therefore, agents with greater hydrophobicity may induce a smaller inhibition zone, despite having a positive effect against the formation of biofilms. In conclusion, this is a test that provides uncertain information about the materials' antimicrobial capacity, not necessarily reflecting the antimicrobial activity neither in vitro nor in vivo [43]. Therefore, we suggest that readers must have caution when reading and interpreting studies of resin-based sealants with antimicrobials that used only the zone of inhibition test to assess the materials' antimicrobial activity.

Other methods such as scanning electron microscopy, confocal laser scanning microscopy, bacterial genomic profiling and tests to analyze the metabolic activity or the capacity to produce essential compounds for biofilm structure are interesting to improve the investigations' quality findings. Few studies used a set of methods to analyze the dental sealants. However, as previously stated, most of them used CFU counting as the primary outcome. This method provides the most predictable effect because it does not depend solely on bacterial metabolic activity, such as the MTT test, or bacterial membrane integrity, such as microscopy with a live/dead kit [44]. CFU essentially relies on bacterial viability. 
Therefore, it is indicated that the CFU results are the main ones considered when analyzing the antimicrobial activity of dental materials with antimicrobial agents [44].

The other concern about the antimicrobial activity tests related to the characteristics of the microbial inoculum used [26,41,42]. From the nineteen studies selected, seventeen tested the dental sealants against $S$. mutans. This bacterium is directly related to the development of caries $[45,46]$. However, dental biofilm is much more complex, involving several microorganisms and microbial interactions, which increases the challenge for antimicrobial dental materials. Although some studies used other microorganisms, such as L. acidophilus, S. oralis, C. albicans, S. salivarius and S. sobrinus, only one study considered the complexity of dental biofilm [21]. This study used multispecies biofilms cultured from pooled saliva of high-caries risk and low-caries risk pediatric dental patients. Currently, we need better in vitro studies that use biofilms with a longer maturation time and microorganisms directly associated with dental caries. The use of biofilms cultured from pooled human saliva seems to be the best alternative for in vitro evaluations to better predict in vivo outcomes. Pooled saliva is recommended to be used to reduce the variation in thickness and densities of biofilms between individuals $[47,48]$.

Among the antibacterial agents/compounds evaluated, those based on quaternary ammonium compounds stand out. This finding is similar to the previous one in the scoping review about antimicrobial agents in restorative resin-based materials, when many studies have tested adhesive systems containing methacryloyloxidodecylpyridinium bromide (MDPB) [26]. Another material frequently found was that composed of fluoride. Fluoride can reduce the metabolic activity of microorganisms or induce the formation of fluorapatite after dental demineralization occurs [49]. Fluorapatite is more resistant to demineralization than hydroxyapatite, making the tooth less susceptible to demineralization when fluoride is present in the environment [49]. However, the study with the highest level of evidence on resinous materials with fluoride shows that other antimicrobial agents, such as MDPB, induce a better antimicrobial effect than materials containing only fluoride [50]. This finding must occur due to the low fluoride concentration capable of being incorporated into resinous materials. With regard to dental sealant types, there is insufficient evidence about the effectiveness of sealants with fluorine compared to other types of sealants [7].

In addition to antimicrobial analyses, many studies have evaluated the physicochemical properties by incorporating antimicrobial agents. Since dental sealants must remain in function, with adhesion to the tooth, and without suffering fractures, the authors must analyze the materials' physicochemical properties. A material that rapidly suffers degradation or exhibits mechanical properties that lead to a loss of function will likely need to be replaced or repaired. The degree of conversion, which analyzes the carbon-carbon double bonds' capacity to convert into carbon-carbon single bonds [51], was the most commonly used test among the studies.

This chemical property is frequently altered by incorporating antimicrobial agents and bioactive charges due to the difference in the refractive index between the resin matrix and the added compounds $[52,53]$. The viscosity of resins after incorporating agents can also be modified, changing the degree of conversion [54] and the adhesion to dental tissues, which is the primary outcome to be assessed. The studies that tested the degree of conversion showed promising results with the incorporation of antimicrobial agents such as $\mathrm{ZnM}$, SnM, DMAHDM, TAT, chitosan and DMAE-CB. The same effect was also found when the adhesion to the tooth structure was tested, such as the shear-bond strength. These findings may be due to the low concentration of agents incorporated in the sealants, which was up to $5 \mathrm{wt} \%$ for most studies. Overall, acceptable physicochemical and antimicrobial properties were found for the sealants with most of the studied antibacterial agents.

There is a trend toward formulating and evaluating dental resin-based sealants with antibacterial agents. Even though there is no standardization among the studies, and most of the studies showed issues related to the risk of bias, most of the studies used the gold-standard test to evaluate the antimicrobial activity, which is a very positive finding. The improving of inoculum source to produce a high challenge scenario for the novel 
dental sealants should be a fundamental goal of the future in vitro studies. The use of more complex methods to better predict antimicrobial results may be the way to accelerate the translation of knowledge from the bench to the clinic.

\section{Conclusions}

In summary, based on the included in vitro studies, the addition of antibacterial agents in resin-based dental sealants could have promising antimicrobial effects. These effects may improve the function of sealants as materials for caries prevention and improve their therapeutic activity. However, standardization of the in vitro studies' protocols and in situ studies and clinical trials to assess these effects and support the findings are recommended.

Author Contributions: Conceptualization, M.S.I.; methodology, M.S.A., M.I.A. and M.S.I.; Covidence software, M.S.A., M.I.A., M.A.A. and M.S.I.; validation, M.S.I., I.M.G. and F.M.C.; formal analysis (data extraction), S.S.A.; resources, M.S.I.; data curation, S.S.A., M.S.A. and M.S.I.; writing-original draft preparation, S.S.A., M.S.A., M.S.I., I.M.G. and F.M.C.; writing-review and editing, M.S.I.; visualization, S.S.A., M.S.A. and M.S.I.; supervision, M.S.I.; project administration, M.S.I.; funding acquisition, None. All authors have read and agreed to the published version of the manuscript.

Funding: This research received no external funding.

Institutional Review Board Statement: Not applicable.

Informed Consent Statement: Not applicable.

Data Availability Statement: No new data were created or analyzed in this study. Data sharing is not applicable to this article.

Acknowledgments: The authors acknowledge the support from Imam Abdulrahman Bin Faisal University.

Conflicts of Interest: The authors declare no conflict of interest.

\section{References}

1. WHO. Oral Health Fact Sheet. 2012. Available online: http://www.who.int/mediacentre/factsheets/fs $318 /$ en/ (accessed on 20 November 2020).

2. Petersen, P.E. The World Oral Health Report 2003: Continuous improvement of oral health in the 21st century-the approach of the WHO Global Oral Health Programme. Community Dent. Oral Epidemiol 2003, 31 (Suppl. 1), 3-23. [CrossRef] [PubMed]

3. Paes Leme, A.F.; Koo, H.; Bellato, C.M.; Bedi, G.; Cury, J.A. The role of sucrose in cariogenic dental biofilm formation-New insight. J. Dent. Res. 2006, 85, 878-887. [CrossRef]

4. Splieth, C.H.; Banerjee, A.; Bottenberg, P.; Breschi, L.; Campus, G.; Ekstrand, K.R.; Giacaman, R.A.; Haak, R.; Hannig, M.; Hickel, R.; et al. How to Intervene in the Caries Process in Children: A Joint ORCA and EFCD Expert Delphi Consensus Statement. Caries Res. 2020, 54, 297-305. [CrossRef]

5. Opdam, N.J.M.; van de Sande, F.H.; Bronkhorst, E.; Cenci, M.S.; Bottenberg, P.; Pallesen, U.; Gaengler, P.; Lindberg, A.; Huysmans, M.C.D.N.J.M.; van Dijken, J.W. Longevity of posterior composite restorations: A systematic review and meta-analysis. J. Dent. Res. 2014, 93, 943-949. [CrossRef] [PubMed]

6. Sheiham, A. Minimal intervention in dental care. Med. Princ. Pract. 2002, 11, 2-6. [CrossRef] [PubMed]

7. Ahovuo-Saloranta, A.; Forss, H.; Walsh, T.; Nordblad, A.; Mäkelä, M.; Worthington, H.V. Pit and fissure sealants for preventing dental decay in permanent teeth. Cochrane Database Syst. Rev. 2017, 7, CD001830. [CrossRef] [PubMed]

8. Fontana, M.; Gonzalez-Cabezas, C. Evidence-Based Dentistry Caries Risk Assessment and Disease Management. Dent. Clin. N. Am. 2019, 63, 119-128. [CrossRef] [PubMed]

9. Delbem, A.C.B.; Brighenti, F.L.; Vieira, A.E.d.M.; Cury, J.A. In vitro comparison of the cariostatic effect between topical application of fluoride gels and fluoride toothpaste. J. Appl. Oral Sci. 2004, 12, 121-126. [CrossRef]

10. Cocco, A.R.; Cuevas-Suárez, C.E.; Liu, Y.; Lund, R.G.; Piva, E.; Hwang, G. Anti-biofilm activity of a novel pit and fissure self-adhesive sealant modified with metallic monomers. Biofouling 2020, 36, 245-255. [CrossRef]

11. Garcia, I.M.; Rodrigues, S.B.; de Souza Balbinot, G.; Visioli, F.; Leitune, V.C.B.; Collares, F.M. Quaternary ammonium compound as antimicrobial agent in resin-based sealants. Clin. Oral Investig. 2020, 24, 777-784. [CrossRef]

12. Monteiro, J.C.; Stürmer, M.; Garcia, I.M.; Melo, M.A.; Sauro, S.; Leitune, V.C.B.; Collares, F.M. Dental Sealant Empowered by 1,3,5-Tri Acryloyl Hexahydro-1,3,5-Triazine and $\alpha$-Tricalcium Phosphate for Anti-Caries Application. Polymers 2020, $12,895$. [CrossRef] [PubMed]

13. Tran, P.; Hamood, A.; Mosley, T.; Gray, T.; Jarvis, C.; Webster, D.; Amaechi, B.; Enos, T.; Reid, T. Organo-selenium-containing dental sealant inhibits bacterial biofilm. J. Dent. Res. 2013, 92, 461-466. [CrossRef] [PubMed] 
14. Iheozor-Ejiofor, Z.; Worthington, H.V.; Walsh, T.; O’Malley, L.; Clarkson, J.E.; Macey, R.; Alam, R.; Tugwell, P.; Welch, V.; Glenny, A.-M. Water fluoridation for the prevention of dental caries. Cochrane Database Syst. Rev. 2015, 2015, CD010856. [CrossRef] [PubMed]

15. Cury, J.A.; de Oliveira, B.H.; dos Santos, A.P.; Tenuta, L.M. Are fluoride releasing dental materials clinically effective on caries control? Dent. Mater. 2016, 32, 323-333. [CrossRef] [PubMed]

16. Bagheri, M.; Pilecki, P.; Sauro, S.; Sherriff, M.; Watson, T.F.; Hosey, M.T. An in vitro investigation of pre-treatment effects before fissure sealing. Int. J. Paediatr. Dent. 2017, 27, 514-522. [CrossRef]

17. Ibrahim, M.S.; AlQarni, F.D.; Al-Dulaijan, Y.A.; Weir, M.D.; Oates, T.W.; Xu, H.H.; Melo, M.A.S. Tuning nano-amorphous calcium phosphate content in novel rechargeable antibacterial dental sealant. Materials 2018, 11, 1544. [CrossRef]

18. GÜÇLÜ, Z.A.; Dönmez, N.; Hurt, A.P.; Coleman, N.J. Characterisation and microleakage of a new hydrophilic fissure sealantUltraSeal XT ${ }^{\circledR}{ }^{\circledR}$ hydro $^{\text {TM }}$. J. Appl. Oral Sci. 2016, 24, 344-351. [CrossRef]

19. Yang, S.-Y.; Kwon, J.-S.; Kim, K.-N.; Kim, K.-M. Enamel surface with pit and fissure sealant containing $45 S 5$ bioactive glass. J. Dent. Res. 2016, 95, 550-557. [CrossRef]

20. Ibrahim, M.S.; Balhaddad, A.A.; Garcia, I.M.; Hefni, E.; Collares, F.M.; Martinho, F.C.; Weir, M.D.; Xu, H.H.K.; Melo, M.A.S. Tooth sealing formulation with bacteria-killing surface and on-demand ion release/recharge inhibits early childhood caries key pathogens. J. Biomed. Mater. Res. B Appl. Biomater. 2020, 108, 3217-3227. [CrossRef]

21. Ibrahim, M.S.; Garcia, I.M.; Vila, T.; Balhaddad, A.A.; Collares, F.M.; Weir, M.D.; Xu, H.H.K.; Melo, M.A.S. Multifunctional antibacterial dental sealants suppress biofilms derived from children at high risk of caries. Biomater. Sci. 2020, 8, 3472-3484. [CrossRef]

22. Ibrahim, M.S.; Balhaddad, A.A.; Garcia, I.M.; Collares, F.M.; Weir, M.D.; Xu, H.H.; Melo, M.A.S. pH-responsive Calcium and Phosphate-Ion Releasing antibacterial Sealants on Carious Enamel lesions in vitro. J. Dent. 2020, 97, 103323. [CrossRef] [PubMed]

23. Lee, M.J.; Kim, J.Y.; Seo, J.Y.; Mangal, U.; Cha, J.Y.; Kwon, J.S.; Choi, S.H. Resin-Based Sealant with Bioactive Glass and Zwitterionic Material for Remineralisation and Multi-Species Biofilm Inhibition. Nanomaterials 2020, 10, 1581. [CrossRef] [PubMed]

24. Liberati, A.; Altman, D.G.; Tetzlaff, J.; Mulrow, C.; Gotzsche, P.C.; Ioannidis, J.P.A.; Clarke, M.; Devereaux, P.J.; Kleijnen, J.; Moher, D. The PRISMA statement for reporting systematic reviews and meta-analyses of studies that evaluate health care interventions: Explanation and elaboration. PLoS Med. 2009, 6, e1000100. [CrossRef] [PubMed]

25. Alamri, A.; Salloot, Z.; Alshaia, A.; Ibrahim, M.S. The Effect of Bioactive Glass-Enhanced Orthodontic Bonding Resins on Prevention of Demineralization: A Systematic Review. Molecules 2020, 25, 2495. [CrossRef] [PubMed]

26. Ibrahim, M.S.; Garcia, I.M.; Kensara, A.; Balhaddad, A.A.; Collares, F.M.; Williams, M.A.; Ibrahim, A.S.; Lin, N.J.; Weir, M.D.; Xu, H.H.K.; et al. How we are assessing the developing antibacterial resin-based dental materials? A scoping review. J. Dent. 2020, 99, 103369. [CrossRef] [PubMed]

27. Ibrahim, M.S.; Ibrahim, A.S.; Balhaddad, A.A.; Weir, M.D.; Lin, N.J.; Tay, F.R.; Oates, T.W.; Xu, H.H.K.; Melo, M.A.S. A Novel Dental Sealant Containing Dimethylaminohexadecyl Methacrylate Suppresses the Cariogenic Pathogenicity of Streptococcus mutans Biofilms. Int. J. Mol. Sci. 2019, 20, 3491. [CrossRef]

28. Swetha, D.L.; Vinay, C.; Uloopi, K.S.; RojaRamya, K.S.; Chandrasekhar, R. Antibacterial and Mechanical Properties of Pit and Fissure Sealants Containing Zinc Oxide and Calcium Fluoride Nanoparticles. Contemp. Clin. Dent. 2019, 10, 477-482. [CrossRef]

29. Zmener, O.; Pameijer, C. Bacterial microleakage of a bioactive pit \&fissure sealant. Am. J. Dent. 2019, 32, $219-222$.

30. Yu, F.; Yu, H.; Lin, P.; Dong, Y.; Zhang, L.; Sun, X.; Liu, Z.; Guo, H.; Huang, L.; Chen, J. Effect of an Antibacterial Monomer on the Antibacterial Activity of a Pit-and-Fissure Sealant. PLOS ONE 2016, 11, e0162281. [CrossRef]

31. Rajabnia, R.; Ghasempour, M.; Gharekhani, S.; Gholamhoseinnia, S.; Soroorhomayoon, S. Anti-Streptococcus mutans property of a chitosan: Containing resin sealant. J. Int. Soc. Prev. Community Dent. 2016, 6, 49-53. [CrossRef]

32. Shanmugaavel, A.; Asokan, S.; John, J.; Priya, P.; Devi, J. Effect of One Percent Chlorhexidine Addition on the Antibacterial Activity and Mechanical Properties of Sealants: An in vitro Study. Int. J. Clin. Pediatric. Dent. 2015, 8, 196-201. [CrossRef]

33. Hamilton, M.; Otte, A.; Gregory, R.; Pinal, R.; Zandoná, A.; Bottino, M. Physicomechanical and antibacterial properties of experimental resin-based dental sealants modified with nylon-6 and chitosan nanofibers. J. Biomed. Mater. Res. Part B Appl. Biomater. 2014, 103. [CrossRef] [PubMed]

34. Mahapoka, E.; Arirachakaran, P.; Watthanaphanit, A.; Rujiravanit, R.; Poolthong, S. Chitosan whiskers from shrimp shells incorporated into dimethacrylate-based dental resin sealant. Dent. Mater. J. 2012, 31, 273-279. [CrossRef]

35. Li, F.; Li, F.; Wu, D.; Ma, S.; Gao, J.; Li, Y.; Xiao, Y.; Chen, J. The Effect of an Antibacterial Monomer on the Antibacterial Activity and Mechanical Properties of a Pit-and-Fissure Sealant. J. Am. Dent. Assoc. 2011, 142, 184-193. [CrossRef]

36. Kumar, M.; Mithun Pai, B.H.; Prashant, G.M.; Reddy, V.S.; Das, U.M.; Madura, C.; Chandu, G.N. Antibacterial Properties of Fluoride Releasing Glass lonomer Cements (GICs) and Pit and Fissure Sealants on Streptococcus Mutans. Int. J. Clin. Pediatr. Dent. 2010, 3, 93-96. [CrossRef]

37. Naorungroj, S.; Wei, H.H.; Arnold, R.R.; Swift, E.J., Jr.; Walter, R. Antibacterial surface properties of fluoride-containing resin-based sealants. J. Dent. 2010, 38, 387-391. [CrossRef]

38. Preetha, V.; Shashikiran, N.; Reddy, V. Comparison of antibacterial properties of two fluoride-releasing and a nonfluoride-releasing pit and fissure sealants. J. Indian Soc. Pedod. Prev. Dent. 2007, 25, 133-136. [CrossRef]

39. Matalon, S.; Slutzky, H.; Mazor, Y.; Weiss, E. Surface antibacterial properties of fissure sealants. Pediatric Dent. 2003, 25, 43-48. 
40. Loyola-Rodriguez, J.; Garcia-Godoy, F. Antibacterial activity of fluoride release sealants on mutans streptococci. J. Clin. Pediatric Dent. 1996, 20, 109-111.

41. Kreth, J.; Ferracane, J.L.; Pfeifer, C.S.; Khajotia, S.; Merritt, J. At the Interface of Materials and Microbiology: A Call for the Development of Standardized Approaches to Assay Biomaterial-Biofilm Interactions. J. Dent. Res. 2019, 98, 850-852. [CrossRef]

42. Kreth, J.; Merritt, J.; Pfeifer, C.S.; Khajotia, S.; Ferracane, J.L. Interaction between the Oral Microbiome and Dental Composite Biomaterials: Where We Are and Where We Should Go. J. Dent. Res. 2020, 99, 1140-1149. [CrossRef]

43. Wanted: A Base of Evidence. J. Endod. 2007, 33, 1401-1402. [CrossRef]

44. Lin, N.J. Biofilm over teeth and restorations: What do we need to know? Dent. Mater. 2017, 33, 667-680. [CrossRef]

45. Eriksson, L.; Lif Holgerson, P.; Esberg, A.; Johansson, I. Microbial Complexes and Caries in 17-Year-Olds with and without Streptococcus mutans. J. Dent. Res. 2018, 97, 275-282. [CrossRef] [PubMed]

46. Forssten, S.D.; Björklund, M.; Ouwehand, A.C. Streptococcus mutans, caries and simulation models. Nutrients 2010, 2, 290-298. [CrossRef]

47. Foster, J.S.; Pan, P.C.; Kolenbrander, P.E. Effects of antimicrobial agents on oral biofilms in a saliva-conditioned flowcell. Biofilms 2004, 1, 5. [CrossRef]

48. Rudney, J.D.; Chen, R.; Lenton, P.; Li, J.; Li, Y.; Jones, R.S.; Reilly, C.; Fok, A.S.; Aparicio, C. A reproducible oral microcosm biofilm model for testing dental materials. J. Appl. Microbiol. 2012, 113, 1540-1553. [CrossRef]

49. Tenuta, L.M.A.; Cury, J.A. Fluoride: Its role in dentistry. Braz. Oral Res. 2010, 24, 9-17. [CrossRef] [PubMed]

50. Pinto, C.F.; Berger, S.B.; Cavalli, V.; Da, S.C.; Goncalves, R.B.; Ambrosano, G.; Giannini, M. In situ antimicrobial activity and inhibition of secondary caries of self-etching adhesives containing an antibacterial agent and/or fluoride. Am. J. Dent. 2015, 28, 167-173.

51. Collares, F.M.; Portella, F.F.; Leitune, V.C.B.; Samuel, S.M.W. Discrepancies in degree of conversion measurements by FTIR. Braz. Oral Res. 2014, 28, 9-15.

52. Par, M.; Spanovic, N.; Mohn, D.; Attin, T.; Tauböck, T.T.; Tarle, Z. Curing potential of experimental resin composites filled with bioactive glass: A comparison between Bis-EMA and UDMA based resin systems. Dent. Mater. 2020, 36, 711-723. [CrossRef] [PubMed]

53. Shortall, A. How light source and product shade influence cure depth for a contemporary composite. J. Oral Rehabil. 2005, 32, 906-911. [CrossRef] [PubMed]

54. Habib, E.; Wang, R.; Zhu, X. Correlation of resin viscosity and monomer conversion to filler particle size in dental composites. Dent. Mater. 2018, 34, 1501-1508. [CrossRef] [PubMed] 